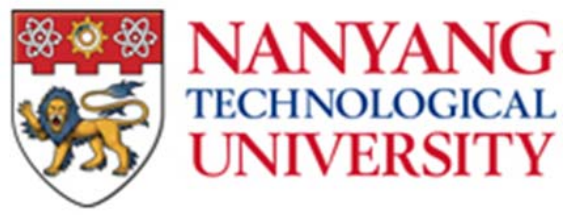

Division of Economics, EGC School of Humanities and Social Sciences

Nanyang Technological University 14 Nanyang Drive Singapore 637332

\title{
Investment Frictions and the Aggregate Output Loss in China
}

\section{Guiying Laura WU}

\author{
31 May 2013 \\ EGC Report No: 2013/07
}

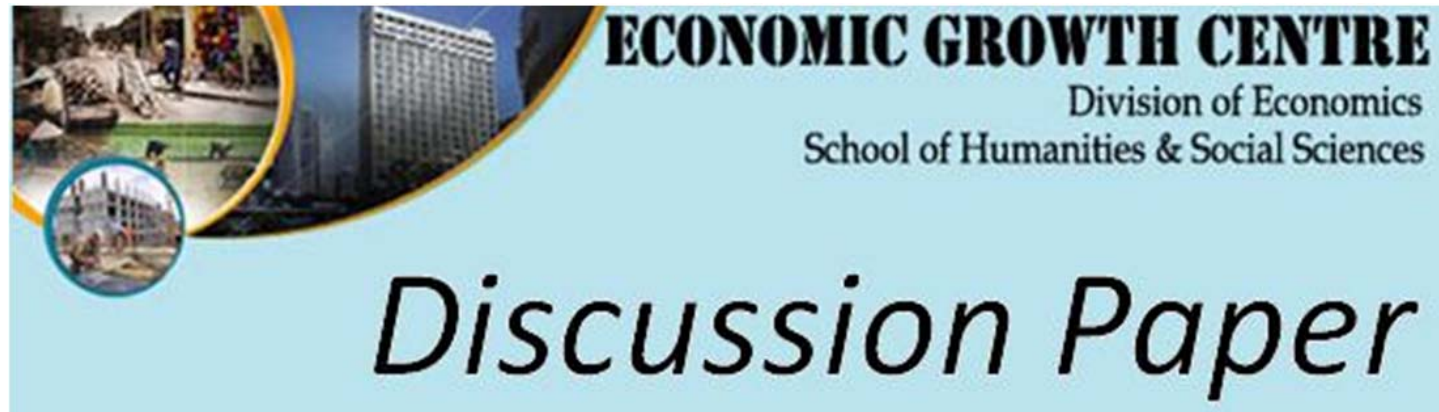


The author(s) bear sole responsibility for this paper.

Views expressed in this paper are those of the author(s) and not necessarily those of the Economic Growth Centre, NTU. 


\title{
Investment Frictions and the Aggregate Output Loss in China*
}

\author{
Guiying Laura Wu \\ Nanyang Technological University
}

May 2013

\begin{abstract}
Investment frictions reduce, delay or protract investment expenditure that is necessary for firms to capture growth opportunities. Using a capital adjustment costs framework, this paper estimates the gap between China's actual and frictionless aggregate output. It applies the method of simulated moments to a fully structural investment model on a panel of Chinese firms; and takes into account potential unobserved heterogeneities and measurement errors in the data. The estimated capital adjustment costs are substantial and vary across firms of different sizes, and across regions with different investment environments. If Chinese firms had faced a lower level of adjustment costs such as in the U.S., China's aggregate output would be $25 \%$ higher.
\end{abstract}

JEL Classification: E22, D92, C15

Key Words: Investment, Capital Adjustment Costs, Method of Simulated Moments

*I would like to thank the editor and anoymous referees for their constructive suggestions; my former supervisors Steve Bond and Måns Söderbom for their invaluable support; and the economists at the Enterprise Analysis Unit of the World Bank for providing the data and explaining the survey. Financial support from the New Silk Road research grant at Nanyang Technological University is gratefully acknowledged. Address: Division of Economics, School of Humanities and Social Sciences, Nanyang Technological University, Singapore, 637332. E-mail: guiying.wu@ntu.edu.sg. 


\section{Introduction}

Substantial economic transformation in China has brought strong growth opportunities and a high return to capital (Song, Storesletten and Zilibotti, 2011). According to neoclassical producer theory, firms will optimally respond to this high return by increasing their investment expenditure, in order to fully capture such growth opportunities. However, as in many developing economies, the actual investment behavior in China might be subject to various frictions, which are caused by a poor investment climate (World Bank, 2005). According to the Doing Business ranking by the World Bank, compared with its counterpart in the U.S., a typical Chinese firm has to spend many more days and pay a much higher cost on starting a business, registering property, getting credit and enforcing contract. Within China, western inland cities like Guiyang and Lanzhou have much poorer indicators than Beijing and Shanghai. ${ }^{1}$ Such investment frictions may prevent the instantaneous and costless adjustment of capital stock and potentially make the actual capital stock different from the frictionless benchmark. An under accumulation of capital stock is then translated into a gap between the actual aggregate output and the first-best aggregate output in an otherwise frictionless environment.

The sharp contrast between strong growth opportunities and large investment frictions motivates the research questions of this paper. For a given investment opportunity, how much lower is the aggregate output in China as a result of investment frictions? How much more would Chinese firms invest and produce if they enjoyed a better investment climate, such as the one that prevails in the U.S.? Would firms in underdeveloped regions catch up had they operated in an environment that is typical of more developed areas within China?

The list of frictions that may affect investment is long and complex. As surveyed in Banerjee and Duflo (2005), specific reasons, such as government failure, poorly functioning credit markets and lack of insurance markets, have been examined to explain large variations in investment across otherwise similar environments. Although each particular friction is of interest, this paper aims to understand the quantitative significance of their overall effects. As such it complements other research which focuses on specific channels.

The neoclassical investment model augmented with capital adjustment costs offers a useful framework to investigate our research questions. In a variety of settings, the investment literature has adopted capital adjustment costs to summarize frictional elements that reduce, delay or protract investment (Khan and Thomas, 2006), while the

\footnotetext{
${ }^{1}$ Appendix 1 presents a list of selected indicators based on which the World Bank has constructed the global and subnational Doing Business ranking as a measure of investment climate.
} 
frictionless investment model offers a first-best benchmark where investment responds to growth opportunities instantaneously and costlessly. Three forms of adjustment cost have been highlighted in this literature: a quadratic adjustment cost, irreversibility and a fixed cost of undertaking any investment (Abel and Eberly, 1994).

Using this framework, the paper estimates the effects of investment frictions on aggregate output loss through capital accumulation. The key challenge in this empirical exercise is to separate capital adjustment costs from other factors that may affect investment as well, in particular, the stochastic process. For example, firms in western inland China exhibit lower and more stagnant investment activities compared to their counterparts in eastern coastal region. Is this because these firms have a lower growth rate, or because they face higher capital adjustment costs, or both? Depending on the answer to this question, the desired policy response could be very different.

To address this identification challenge, this paper adopts a fully structural econometric approach. It specifies the complete environment in which investment decisions are taken: the Jorgensonian user cost of capital, production technology, demand schedule, stochastic process, and different forms of adjustment costs. The exact investment policies are then solved out for the structural parameters that characterize the environment. These deep or primitive parameters are estimated using a method of simulated moments, which matches simulated model moments with empirical moments from a panel of Chinese firms. This empirical exercise therefore indirectly infers the overall investment frictions facing these Chinese firms, by asking how large the capital adjustment costs must be so as to be consistent with the observed investment behavior.

The main findings of this paper are as follows. First, there are substantial capital adjustment costs for the whole sample. These costs imply that China's aggregate output is $31 \%$ below the frictionless benchmark. Second, subsample estimation detects significant differences in the quadratic adjustment costs across firms of different sizes, and across regions with different investment climates. If all the firms in China had faced a lower level of adjustment costs such as in the U.S., China's aggregate output would be $25 \%$ higher. Within China, the output gain could be as large as one-third for small firms and one-quarter for firms in western inland cities.

This research is most closely related to two seminal papers, Cooper and Haltiwanger (2006) and Bloom (2009), in terms of methodology. However, there are three important novelties that are worth highlighting.

First, in addition to investment and sales growth rates, this paper also matches moments of profit to sales ratio and sales to capital ratio. The information in these two ratios allows the model to flexibly estimate the production technology and demand schedule, which are usually taken as given in previous researches .

Second, although unobserved heterogeneity prevails in micro-level data, it has not 
been explicitly taken into account by the part of the investment literature using structural estimation. This paper models and estimates unobserved heterogeneities in the capital share of the production technology and in the growth rate of the stochastic process. Allowing for such heterogeneities is crucial, both for consistent estimation of the adjustment costs, and for an accurate interpretation of the results.

Finally, one common feature of survey data is the possibility of significant measurement error in recorded variables, especially in stock variables such as capital. This paper therefore estimates measurement error in capital stock simultaneously with the true model. It helps to match some important features of the data, and hence improves the overall fit substantially.

Section 2 outlines the investment model and defines the aggregate output loss. Section 3 presents the data and introduces the empirical specification. Section 4 discusses the identification strategy and the structural econometric approach. Section 5 reports the empirical results and provides the counterfactual simulations. Section 6 concludes the paper and discusses directions for future research.

\section{The Model}

Our analysis is based on a standard model in the investment literature, such as Abel and Eberly (1994). It considers how an ongoing representative firm optimally makes its investment decision, in a partial equilibrium framework where investment opportunities are exogenously given. As usual, a static instantaneous operating profit function can first be obtained by optimizing out variable inputs. The intertemporal investment decision is then derived by maximizing the discounted sum of future net profits in the presence of capital adjustment costs.

\subsection{Production and Demand}

By paying capital adjustment costs, in each period $t$ new investment $I_{t}$ contributes to productive capital $\widehat{K}_{t}$ immediately, which depreciates at the end of each period at a constant rate $\delta .{ }^{2}$ The law of motion for capital stock is therefore

$$
K_{t+1}=(1-\delta)\left(K_{t}+I_{t}\right) \equiv(1-\delta) \widehat{K}_{t}
$$

Consider a firm that uses capital stock $\widehat{K}_{t}$, and a vector of variable inputs $L_{t}$ (such as labor, material and management) to produce output $Q_{t}$, according to a stochastic

\footnotetext{
${ }^{2}$ An alternative timing assumption would be $K_{t+1}=(1-\delta) K_{t}+I_{t}$. Qualitatively this and equation (1) have the same implications. However, equation (1) allows for a closed-form solution to the investment problem in the frictionless case, which does not involve any expectation terms. This provides a convenient benchmark for studying the effects of capital adjustment costs.
} 
constant returns to scale Cobb-Douglas technology,

$$
Q_{t}=A_{t} \widehat{K}_{t}^{\beta} L_{t}^{1-\beta}
$$

where $A_{t}$ represents the randomness in productivity and the capital share $\beta$ satisfies $0<\beta<1 .^{3}$ The firm faces monopolistic competition in the product market. Assume an isoelastic, downward-sloping, stochastic demand curve,

$$
Q_{t}=X_{t} P_{t}^{-\varepsilon}
$$

where $X_{t}$ represents the randomness in demand; $-\varepsilon<-1$ is the demand elasticity with respect to price.

In any period $t$, for a given predetermined capital stock, productivity and demand realization, the firm chooses a vector of variable inputs $L_{t}$ to maximize its operating profit,

$$
\pi_{t}=\max _{L_{t}}\left\{Y_{t}-w L_{t}\right\}
$$

where $Y_{t} \equiv P_{t} Q_{t}$ denotes sales revenue, and $w$ is a constant vector containing the prices of variable inputs. The first-order condition implies a constant cost share for variable inputs,

$$
\frac{w L_{t}}{Y_{t}}=(1-\beta)\left(1-\frac{1}{\varepsilon}\right) .
$$

Therefore the aggregate output loss also means the same magnitude of aggregate variable inputs loss, for example, a lower level of employment. ${ }^{4}$ Optimization then yields the maximized value of operating profit,

$$
\pi_{t}\left(Z_{t}, \widehat{K}_{t}\right)=\frac{h}{1-\gamma} Z_{t}^{\gamma} \widehat{K}_{t}^{1-\gamma}
$$

where $Z_{t}=X_{t}\left(A_{t}\right)^{\varepsilon-1}, h=(1-\gamma)\left(\frac{\gamma \varepsilon-1}{w}\right)^{\gamma \varepsilon-1}(\gamma \varepsilon)^{-\gamma \varepsilon}$, and

$$
\gamma=\frac{1}{1+\beta(\varepsilon-1)},
$$

capturing the curvature of the operating profit function. The linear homogeneity of the production technology and the isoelastic demand schedule imply that the maximized operating profit is always a constant proportion of sales,

$$
\frac{\pi_{t}}{Y_{t}}=\frac{1}{\gamma \varepsilon}=\beta\left(1-\frac{1}{\varepsilon}\right)+\frac{1}{\varepsilon} .
$$

\footnotetext{
${ }^{3}$ As surveyed by Ackerber, Benkard, Berry and Pakes (2007), in the large literature of production function estimation, both in advanced economies such as the U.S. (Blundell and Bond, 2000) and in many developing countries (Söderbom and Teal, 2004), constant return to scale is a specification that is not generally rejected by the data. Since labor share is relatively poorly measured in China, this paper only uses information on capital share to estimate $\beta$ and regulates the labor share as $1-\beta$ under the constant return to scale restriction.

${ }^{4} \mathrm{I}$ acknowledge one referee for pointing this out, since employment is an important policy target for a country like China, which has a large population and concerns about stability.
} 
Together with equation (2), this property implies a sales revenue as below:

$$
Y_{t}\left(Z_{t}, \widehat{K}_{t}\right)=\frac{\gamma \varepsilon h}{1-\gamma} Z_{t}^{\gamma} \widehat{K}_{t}^{1-\gamma}
$$

The sales and profit function use $Z_{t}$ to incorporate stochastic variations from both $X_{t}$ and $A_{t}$. Following Foster, Haltiwanger and Syverson (2008), this paper calls $Z_{t}$ the revenue total factor productivity or revenue TFP. This is to emphasize that the stochastic variations in the revenue function could come from both demand and productivity shocks. Assume $Z_{t}$ is a trend stationary process with growth rate $\mu$ and serial correlation $\rho$. The standard deviation $\sigma$ of the innovations characterizes the level of uncertainty in this model. That is,

$$
\begin{aligned}
\log Z_{t} & =\mu t+z_{t}, \\
z_{t} & =\rho z_{t-1}+e_{t},
\end{aligned}
$$

where $0<\rho<1, e_{t} \stackrel{i . i . d .}{\sim} N\left(0, \sigma^{2}\right)$, and $z_{0}=0$.

\subsection{Investment Frictions and Capital Adjustment Costs}

In contrast to variable inputs, various investment frictions prevent instantaneous and costless adjustment of the capital stock. To seek for the driving force of investment frictions, the World Bank's Doing Business ranking has considered factors in the ease of getting credit, getting electricity, paying taxes, trading across borders, registering property, protecting investors, enforcing contracts, starting a business, dealing with construction permits and closing a business. To provide a modeling mechanism, the investment literature has adopted three forms of capital adjustment costs to capture the effects of various investment frictions on investment behavior.

Traditionally the investment literature has used quadratic adjustment costs to model certain frictions that prevent firms from immediately attaining their chosen capital levels, instead through a series of gradual, partial adjustment towards these target levels over time. For example, difficulties in getting credit and electricity and bureaucracies in paying taxes and trading across borders may affect investment in the way of quadratic adjustment costs.

Partial irreversibility is another form of adjustment costs that has been widely examined in investment theory. It reflects the adverse selection problem in the secondhand capital goods market, or more generally the wait-and-see behavior in investment decisions. For example, difficult property registration, weak investor protection and poor contract enforcement will make firms more conservative in their investment expenditure, and sometimes even cause them to do no investment at all.

More recently, fixed adjustment costs have been introduced into the literature to reflect the indivisibility in capital, or more generally the lumpiness in investment. 
For example, a high cost of starting a subplant in a new business line, dealing with construction permits for a large investment project, or closing a loss-making subplant, can be modelled as a form of fixed adjustment costs. ${ }^{5}$

Following the functional form in Cooper and Haltiwanger (2006) and Bloom (2009), these capital adjustment costs can be summarized by the adjustment cost function:

$$
G\left(Z_{t}, K_{t} ; I_{t}\right)=\frac{b_{q}}{2}\left(\frac{I_{t}}{K_{t}}\right)^{2} K_{t}-b_{i} I_{t} \mathbf{1}_{\left[I_{t}<0\right]}+b_{f} \mathbf{1}_{\left[I_{t} \neq 0\right]} \pi_{t},
$$

where $\mathbf{1}_{\left[I_{t}<0\right]}$ and $\mathbf{1}_{\left[I_{t} \neq 0\right]}$ are indicators for negative and non-zero investment. $b_{q}$ measures the magnitude of quadratic adjustment costs. $b_{i}$ reflects the significance of irreversibility and can be interpreted as the difference between the purchase price and the resale price, expressed as a percentage of the purchase price of capital goods. The fixed adjustment $\operatorname{cost} b_{f}$ is interpreted as the fraction of operating profit loss due to any non-zero investment.

\subsection{Investment Decision}

Normalizing the price of capital to one, the firm's net profit in each period $t$ is therefore

$$
\Pi\left(Z_{t}, K_{t} ; I_{t}\right)=\pi\left(Z_{t}, K_{t} ; I_{t}\right)-G\left(Z_{t}, K_{t} ; I_{t}\right)-I_{t}
$$

Suppose the owner of the firm discounts future net profits at a constant rate $r$. The optimal investment problem can be represented as the solution to a dynamic optimization problem defined by the stochastic Bellman equation

$$
V\left(Z_{t}, K_{t}\right)=\max _{I_{t}}\left\{\Pi\left(Z_{t}, K_{t} ; I_{t}\right)+\frac{1}{1+r} E_{t}\left[V\left(Z_{t+1}, K_{t+1}\right)\right]\right\}
$$

together with the law of motion (1) and (6) for $K_{t}$ and $Z_{t}$.

In the benchmark case of no adjustment cost, that is when $G\left(Z_{t}, K_{t} ; I_{t}\right)=0$, it is straightforward to solve out the the optimal productive capital stock

$$
\widehat{K}_{t}^{*} \equiv\left(I_{t}+K_{t}\right)^{*}=H Z_{t}
$$

and the optimal investment rate

$$
\left(\frac{I_{t}}{K_{t}}\right)^{*}=H\left(\frac{Z_{t}}{K_{t}}\right)-1
$$

where

$$
H=\left(\frac{h}{J}\right)^{\frac{1}{\gamma}}
$$

\footnotetext{
${ }^{5}$ There is a large body of literature on the economic rationale for why different forms of capital adjustment costs may be utilized to model the effects of various investment frictions on investment behavior. Recent surveys include Chirinko (1993), Hamermesh and Pfann (1996), and Khan and Thomas (2006).
} 
and

$$
J=\frac{r+\delta}{1+r} .
$$

Here $J$ is known as the Jorgensonian user cost of capital. Intuitively, without any friction the optimal investment rate $\left(\frac{I_{t}}{K_{t}}\right)^{*}$ is a linear function of revenue TFP $Z_{t}$ relative to inherited capital stock $K_{t}$ to meet the imbalance between the optimal productive capital stock $\widehat{K}_{t}^{*}$ and the level of revenue TFP $Z_{t}$ in each period. This optimality condition also implies a constant frictionless sales to capital ratio

$$
\left(\frac{Y_{t}}{\widehat{K}_{t}}\right)^{*}=\frac{J}{\beta\left(1-\frac{1}{\varepsilon}\right)} .
$$

When $G\left(Z_{t}, K_{t} ; I_{t}\right)>0$, the optimal investment policy can be solved out using numerical dynamic programming methods. Figures 1a to 1c illustrate these policies under different forms of adjustment costs, where the 45 degree lines are plotted as the frictionless benchmark equation (9). First of all, irrespective of the form of adjustment costs, the optimal investment policy is always a non-decreasing function of $\left(\frac{Z_{t}}{K_{t}}\right)$. With respect to each particular form of adjustment costs, when $b_{q}>0$, capital accumulation is through a series of small and continuous adjustments. This is consistent with the prediction of the convex adjustment cost literature, such as Abel (1983). When $b_{i}>0$, there is a familiar region of inaction in the investment rate as predicted by the irreversibility literature, represented by Dixit and Pindyck (1994), where the optimal investment decision is characterized as a 'barrier control' policy. When $b_{f}>0$, lumpiness in the investment rate implies that the optimal investment decision can be characterized as a 'jump control' policy, as documented by Doms and Dunne (1998) in the fixed adjustment cost literature.

\subsection{Aggregate Output Loss}

According to equation (5), for a representative firm $i$ in year $t$, the actual and firstbest sales revenue are $Y_{i, t}=\frac{\gamma \varepsilon h}{1-\gamma} Z_{i, t}^{\gamma} \widehat{K}_{i, t}^{1-\gamma}$ and $Y_{i, t}^{*}=\frac{\gamma \varepsilon h}{1-\gamma} Z_{i, t}^{\gamma} \widehat{K}_{i, t}^{* 1-\gamma}$, respectively. For an economy with $N$ firms, define the aggregate output loss as the average of the differences between $Y_{i, t}$ and $Y_{i, t}^{*}$, which is driven by the differences between the actual productive capital stock $\widehat{K}_{i, t}$ and the frictionless productive capital stock $\widehat{K}_{i, t}^{*}$ :

$$
\begin{aligned}
\Delta \log \mathbf{Y}_{t} & \equiv \frac{1}{N} \sum_{i=1}^{N}\left(\log Y_{i, t}-\log Y_{i, t}^{*}\right) \\
& =(1-\gamma) \frac{1}{N} \sum_{i=1}^{N}\left(\log \widehat{K}_{i, t}-\log \widehat{K}_{i, t}^{*}\right) \\
& \equiv(1-\gamma) \Delta \log \mathbf{K}_{t}
\end{aligned}
$$

For a given Jorgensonian user cost of capital, production technology, demand schedule and a realization of revenue TFP, the frictionless capital stock $\widehat{K}_{i, t}^{*}$ can be solved 
out according to equation (8). In addition to these factors, the actual capital stock $\widehat{K}_{i, t}$ also depends on the capital adjustment costs facing the firm. It is such costs at the firm level that are translated into an output loss at the aggregate level according to equation (12).

However, without a closed-form solution to the investment problem in the presence of adjustment costs, it is unclear whether $\widehat{K}_{i, t}$ is higher or lower than $\widehat{K}_{i, t}^{*}$ and by how much. When $b_{i}>0$, Abel and Eberly (1999) demonstrate that irreversibility may increase or decrease capital accumulation due to the opposite user cost effect and hangover effect. ${ }^{6}$ When $b_{q}>0$, Bond, Söderbom and Wu (2011) show that the capital stock would be unambiguously lower than in the frictionless case, because any capital adjustment incurs a cost in addition to the Jorgensonian user cost of capital. If $b_{f}>0$, $\mathrm{Wu}$ (2009) shows that the effect of fixed adjustment costs on capital accumulation is similar to quadratic adjustment costs under complete certainty, and is similar to irreversibility in an uncertain environment. This implies that the effects of adjustment costs on aggregate output loss is in fact an empirical question.

\subsection{A First-Order Approximation in a Special Case}

To provide an intuitive example on how capital adjustment costs may cause an aggregate output loss, consider a special case when there is quadratic adjustment cost only. That is when $b_{q}>0$ and $b_{i}=b_{f}=0$. This special case allows for a closed-form investment Euler equation so that the actual capital stock can be approximated as

$$
\widehat{K}_{i, t}=\left(\frac{h}{U}\right)^{\frac{1}{\gamma}} Z_{i, t},
$$

where $U$ is the generalized user cost of capital,

$$
U \simeq J\left(1+b_{q} \frac{I_{i, t}}{K_{i, t}}\right)
$$

Comparison between equations (10) and (14) highlights the fact that in the presence of quadratic adjustment costs, the actual user cost of capital is an amplification of the Jorgensonian user cost of capital. The magnitude of the amplification depends on both the quadratic adjustment $\operatorname{costs} b_{q}$ and the investment rate $\frac{I_{i, t}}{K_{i, t}}$. All else being equal, a larger generalized user cost of capital will unambiguously lead to lower capital stock levels. It is in this sense that quadratic adjustment costs may function as a

\footnotetext{
${ }^{6}$ To be specific, the "user cost effect" occurs because the firm anticipates that the irreversibility constraint may bind in the future and thus is more reluctant to invest today, so that the capital stock under irreversibility is smaller than that under reversibility. The "hang over effect" indicates the dependence of the current capital stock on past behavior, especially behavior that later the firm would like to reverse, which can lead to a higher capital stock under irreversibility than under reversibility.
} 
generic representation of various investment frictions on capital accumulation through the user cost of capital.

Together with equations (8) and (13), the aggregate output loss now has a convenient first-order approximation,

$$
\Delta \log \mathbf{Y}_{t} \simeq-\frac{1-\gamma}{\gamma} b_{q} \frac{1}{N} \sum_{i=1}^{N} \frac{I_{i, t}}{K_{i, t}}
$$

Different from conventional empirical exercises, it is not possible to estimate $b_{q}$ by regressing equation (15) since $\Delta \log \mathbf{Y}_{t}$ is not observable. Instead, $\Delta \log \mathbf{Y}_{t}$ itself is the quantity of our interest, which depends on the deep or primitive parameters of the investment model, such as $\gamma$ and $b_{q}$. This motivates the structural econometric approach adopted in this paper, which indirectly infers model parameters by matching model simulated data with the Chinese firm-level data described below.

\section{Data and Empirical Specification}

\subsection{Data and Variables}

The dataset comes from two World Bank Investment Climate Surveys, which were conducted in China in 2001 and 2003 respectively. The combined sample includes 3948 firms distributed across 15 industries and 23 cities of China. Compared with potential alternatives such as the China's Industrial Survey dataset, the dataset that we use has two important advantages. First, the sample of firms is stratified by size and therefore includes a large number of small firms. These firms are of particular interest because according to conventional wisdom, they are most likely to face an unfavorable investment climate in developing countries. However, such firms are excluded from the Industrial Survey, which only samples firms whose sales revenue exceeds 5 million Chinese yuan. Second, the Investment Climate Survey explicitly asks about the investment expenditure on fixed assets for each firm in each year. Accurate information on investment is crucial in estimating any investment model. However, such information is not available in the Industrial Survey.

Four key variables are collected from the data for this analysis. They are: investment $\left(I_{i, t}\right)$ : value of investment expenditure net of value of disinvestment in machinery, equipment and firm; capital stock $\left(K_{i, t}\right)$ : net book value of machinery, equipment and firm; sales revenue $\left(Y_{i, t}\right)$ : total value of sales plus change in inventory of finished goods; and operating profit $\left(\pi_{i, t}\right)$ : sales net of costs of raw materials and inputs, total energy costs, total labour costs and other overhead costs, where $i$ denotes firm and $t$ denotes year.

For this empirical exercise, four variables in level-form are used to construct five key variables which are either ratios or growth rates. These five variables are investment 
rate $\left(I_{i, t} / K_{i, t}\right)$; real sales growth rate $\left(\Delta \log Y_{i, t} \equiv \log Y_{i, t}-\log Y_{i, t-1}\right)$; profit to sales ratio $\left(\pi_{i, t} / Y_{i, t}\right)$; $\log$ sales to productive capital ratio $\left(\log \left(Y_{i, t} / \widehat{K}_{i, t}\right)\right)$ as a measure of capital intensity, and log sales to beginning-of-period capital ratio $\left(\log \left(Y_{i, t} / K_{i, t}\right)\right)$ as a proxy for the marginal revenue product of capital ( $M R P K$, hereafter).

The Data Appendix provides further information about sampling, how these variables are deflated and cleaned, together with the macroeconomic background for China during our sample period.

Figure 2a plots the empirical distribution of the investment rate $I_{i, t} / K_{i, t}$. The most distinctive feature is a considerable mass at zero. The second feature is that although the investment rate is highly dispersed, very few firms have negative investment rates. Therefore, there is a striking asymmetry between investment and disinvestment and the distribution is highly skewed to the right. Figure $2 \mathrm{~b}$ illustrates the empirical distribution of the sales growth rate $\Delta \log Y_{i, t}$, and shows that it is also very dispersed. However unlike the investment rate, the distribution of the sales growth rate is much more symmetric, around a mean of approximately $9 \%$. Figure $2 \mathrm{c}$ is the empirical distribution of $\log \left(Y_{i, t} / \widehat{K}_{i, t}\right)$, which is very similar to that of $\log \left(Y_{i, t} / K_{i, t}\right)$. Both variables are highly dispersed and distributed symmetrically abound 0.55 .

Figures $3 \mathrm{a}$ to $3 \mathrm{c}$ plot the cross correlations between the investment rate $I_{i, t} / K_{i, t}$, sales growth rate $\Delta \log Y_{i, t}$ and $\log$ sales to capital ratio $\log \left(Y_{i, t} / K_{i, t}\right)$. As highlighted in these figures, both the investment and sales growth rates respond to the proxy of $M R P K$ positively, and they are also positively correlated with each other. However, the flat fitted lines also indicate a dampened response and a low correlation, which is consistent with the importance of capital adjustment costs, as simulated in Figures 1a to $1 \mathrm{c}$

\subsection{Identification and Empirical Specification}

\subsubsection{Capital Share Heterogeneity}

The first novelty in our empirical specification is to consider potential heterogeneity in the capital share of the production function $(\beta)$. This is motivated by the following consideration. First, firms in this analysis are sampled from various industries which may have different production technology; even within the same industry, the production technology could be firm-specific. Second, Figure 2c highlights the large dispersion in $\log \left(Y_{i, t} / \widehat{K}_{i, t}\right)$ and $\log \left(Y_{i, t} / K_{i, t}\right)$. Recall that in the absence of adjustment costs $\log \left(Y_{i, t} / \widehat{K}_{i, t}\right)$ would be a constant as in equation (11). Both adjustment costs and heterogeneity in $\beta$ could cause a dispersion in $\log \left(Y_{i, t} / \widehat{K}_{i, t}\right)$. Therefore not allowing for potential heterogeneity in $\beta$ might cause an overestimate of the adjustment costs. Similarly, $\log \left(Y_{i, t} / K_{i, t}\right)$ has served as a proxy for $M R P K$ so that 
capital adjustment costs can be inferred by how the investment rate $I_{i, t} / K_{i, t}$ responds to this proxy according to equation (9). Since heterogeneity in $\beta$ will cause dispersion in $\log \left(Y_{i, t} / K_{i, t}\right)$, both adjustment costs and heterogeneity in $\beta$ could reduce the correlation between $I_{i, t} / K_{i, t}$ and $\log \left(Y_{i, t} / K_{i, t}\right)$. This also implies that not allowing for potential heterogeneity in $\beta$ may overestimate the adjustment costs. ${ }^{7}$ The symmetric empirical distribution of $\log \left(Y_{i, t} / \widehat{K}_{i, t}\right)$ suggests that $\beta$ can be assumed to be log-normally distributed.

\section{Assumption 1 Capital Share Heterogeneity: $\log \beta_{i} \stackrel{i . i . d}{\sim} N\left(\mu_{\log \beta}, \sigma_{\log \beta}^{2}\right)$}

That is each firm $i$ has a firm-specific capital share $\beta_{i}$, where $\log \beta_{i}$ is drawn independently from an identical normal distribution with mean $\mu_{\log \beta}$ and standard deviation $\sigma_{\log \beta}$.

\subsubsection{Growth Rate Heterogeneity}

The second empirical feature taken into account is the potential heterogeneity in the growth rate of revenue TFP $(\mu)$. There are three reasons why modelling this heterogeneity is important. First, we pool data across surveys which themselves are spanning across years and regions. Heterogeneity in the growth rate is one way to characterize some year-specific and region-specific effects. Second, as recognized in both Cooper and Haltiwanger (2006) and Bloom (2009), a key challenge in estimating adjustment costs is to distinguish permanent differences in the stochastic process from adjustment costs. For example, heterogeneity in $\mu$ across firms, as well as high quadratic adjustment costs, can both lead to persistent differences across firms in their investment rates. Finally, a key challenge in estimating the stochastic process itself is to distinguish permanent differences in the growth rate from a highly serially correlated driving process (Browning, Ejrnaes and Alvarez, 2010). For example, both heterogeneity in $\mu$ and a highly serially correlated driving process can lead to persistent differences across firms in their sales growth rates. The empirical distribution of $\Delta \log Y_{i, t}$ suggests that a normality assumption on the distribution of $\mu$ may be appropriate. ${ }^{8}$

Assumption 2 Growth Rate Heterogeneity: $\mu_{i} \stackrel{i . i . d}{\sim} N\left(\mu_{\mu}, \sigma_{\mu}^{2}\right)$

\footnotetext{
${ }^{7}$ All these arguments also apply to potential heterogeneity in the demand elasticity $\varepsilon$. However, without separate information about thequantity of output $\left(Q_{i, t}\right)$ and the price of product $\left(P_{i, t}\right)$, one cannot further distinguish heterogeneity in $\beta$ from that in $\varepsilon$ in this model. Hence we assume homogeneity in demand elasticity and heterogeneity in capital share.

${ }^{8}$ Bloom (2000) shows that, despite the presence of adjustment costs, in the long run both capital stock and sales will grow at the same rate as the revenue TFP in this model. This is essentially because when a firm is on its balanced growth path, the gap between friction and frictionless capital stock is bounded so that $\Delta \log Y_{i, T} \equiv \lim _{T \rightarrow \infty} \frac{1}{T} \ln \left(Y_{i, T+t} / Y_{i, t}\right)=\lim _{T \rightarrow \infty} \frac{1}{T} \ln \left(\widehat{K}_{i, T+t} / \widehat{K}_{i, t}\right)=$ $\lim _{T \rightarrow \infty} \frac{1}{T} \ln \left(Z_{i, T+t} / Z_{i, t}\right)=\mu_{i}$.
} 
That is each firm $i$ has a firm-specific revenue TFP growth rate $\mu_{i}$, where $\mu_{i}$ is drawn independently from an identical normal distribution with mean $\mu_{\mu}$ and standard deviation $\sigma_{\mu}$.

The investment policy under different $\left(\beta_{i}, \mu_{i}\right)$ is different. Accordingly the optimization problem described in equation (7) must be solved for each firm $i$ at each value of $\left(\beta_{i}, \mu_{i}\right)$, which is infeasible even for a small sample due to the "curse of dimensionality". Therefore this paper adopts a standard approach used in the literature modelling unobserved heterogeneities, for example, Eckstein and Wolpin (1999), to allow for a finite number of firm types.

Assumption 3 Finite Type of Firms: There are $3 \times 3$ types of firms, each comprising a fixed proportion $1 /(3 \times 3)$ of the population, where the type set is defined as $\digamma=\left\{\left(\beta_{v}, \mu_{x}\right): v=1,2,3 ; x=1,2,3\right\}$.

\subsubsection{Measurement Error}

In addition to a rich structure of heterogeneities, our empirical specification also allows for potential measurement error in capital stock. This is motivated by two facts. First, measurement errors are common in micro-level data, and the capital stock is usually poorly measured. Second and more fundamentally, measurement error in capital stock $K_{i, t}$ will affect key variables such as $I_{i, t} / K_{i, t}$ and $\log \left(Y_{i, t} / K_{i, t}\right)$. Given capital adjustment costs are inferred from the distribution and dynamics of these ratios, neglecting such measurement error may lead to inconsistency in the estimation. In reality the form of measurement error could be very complicated. The specification we consider below has three advantages. First, it guarantees positive values for capital stock. Second, it does not change the sign of recorded investment rate. Finally, by construction, it does not contaminate identification of other model parameters.

\section{Assumption 4 Measurement error in capital stock:}

$$
K_{i, t}=K_{i, t}^{\prime} \exp \left(e_{i, t}^{K}\right), \text { where } e_{i, t}^{K} \stackrel{i . i . d}{\sim} N\left(0, \sigma_{m e K}^{2}\right)
$$

Here $K_{i, t}$ denotes the observed capital stock, $K_{i, t}^{\prime}$ denotes the true underlying capital stock which is not measured accurately in the data. The measurement error has a multiplicative structure, with mean zero and standard deviation $\sigma_{m e K}$.

\section{Structural Estimation}

The structural parameters in the model are estimated by the method of simulated moments (MSM). This methodology has been widely employed in the recent empirical 
investment literature using micro-level data. ${ }^{9}$ Intuitively, the MSM estimates a set of structural parameters by minimizing the quadratic distance between a set of simulated moments from the model and the same set of empirical moments from the data. Since different specifications may match some moments more precisely than others, the MSM gives each moment a weight in calculating the quadratic distance, which shares exactly the same idea as GMM. The key point of this methodology is that the value of the simulated moments depends on the structural parameters imposed in each round of simulation. Therefore, if the model is well specified, the distance between the moments is minimized at the optimal estimates of the parameters.

\subsection{Method of Simulated Moments}

Formally, following Gouriéroux and Monfort (1996), the MSM estimator $\Theta^{*}$ solves

$$
\widehat{\Theta}^{*}=\arg \min _{\Theta}\left(\widehat{\Phi}^{D}-\frac{1}{S} \sum_{s=1}^{S} \widehat{\Phi}_{s}^{M}(\Theta)\right)^{\prime} \Omega\left(\widehat{\Phi}^{D}-\frac{1}{S} \sum_{s=1}^{S} \widehat{\Phi}_{s}^{M}(\Theta)\right),
$$

where $\Theta$ is the vector of parameters of interest; $\widehat{\Phi}^{D}$ is a set of empirical moments estimated from an empirical dataset; $\widehat{\Phi}^{M}(\Theta)$ is the same set of simulated moments estimated from a simulated dataset based on the structural model; $S$ is the number of simulation paths; and $\Omega$ is a positive definite weighting matrix.

Suppose the empirical dataset is a panel with $N$ firms and $T$ years. Given the unobserved heterogeneities across firms, the asymptotic results are for fixed $T$ and $N \rightarrow \infty$. At the efficient choice for the weighting matrix $\Omega^{*}$, the MSM procedure provides a global specification test of the overidentifying restrictions of the model:

$$
\begin{aligned}
O I & =\frac{N S}{1+S}\left(\widehat{\Phi}^{D}-\frac{1}{S} \sum_{s=1}^{S} \widehat{\Phi}_{s}^{M}(\Theta)\right)^{\prime} \Omega^{*}\left(\widehat{\Phi}^{D}-\frac{1}{S} \sum_{s=1}^{S} \widehat{\Phi}_{s}^{M}(\Theta)\right) \\
& \sim \chi^{2}[\operatorname{dim}(\widehat{\Phi})-\operatorname{dim}(\Theta)] .
\end{aligned}
$$

If the optimal weighting matrix $\Omega^{*}$ is used in solving (16), the MSM estimator is asymptotically normal for fixed $S$ and $T$, and $N \rightarrow \infty$, i.e.

$$
\sqrt{N}\left(\widehat{\Theta}-\Theta^{*}\right) \stackrel{D}{\rightarrow} N\left(0, W\left(S, \Omega^{*}\right)\right),
$$

where

$$
W\left(S, \Omega^{*}\right)=\left(1+\frac{1}{S}\right)\left(E\left[\partial \widehat{\Phi}^{M}(\widehat{\Theta})^{\prime} / \partial \Theta\right] \Omega^{*} E\left[\partial \widehat{\Phi}^{M}(\widehat{\Theta}) / \partial \Theta^{\prime}\right]\right)^{-1} .
$$

\footnotetext{
${ }^{9}$ For example, in addition to Cooper and Haltiwanger (2006) and Bloom (2009), Cooper and Ejarque (2003) and Eberly, Rebelo and Vincent (2008) evaluate the $Q$-model; Bond, Söderbom and $\mathrm{Wu}(2008)$ study the effects of uncertainty on capital accumulation; Schündeln (2006), Henessy and Whited (2007) and Bond, Söderbom and Wu (2007) estimate the cost of financing investment; Fafchamps and Söderbom (2006) and Cooper, Gong and Yan (2011) investigate the dynamic labor demand, all through this structural econometric approach.
} 


\subsection{Identification Strategy}

The data simulated from this investment model are determined by five factors: the Jorgensonian user cost of capital $(r, \delta)$, production technology $\left(\mu_{\log \beta}, \sigma_{\log \beta}\right)$, demand schedule $(\varepsilon)$, the stochastic process characterizing serial correlation $(\rho)$, growth $\left(\mu_{\mu}, \sigma_{\mu}\right)$, uncertainty $(\sigma)$, different forms of adjustment costs $\left(b_{q}, b_{i}, b_{f}\right)$, and measurement error $\left(\sigma_{m e K}\right)$.

In a model without any heterogeneity and measurement error, by imposing other factors and pre-estimating the stochastic process, Cooper and Haltiwanger (2006) indicate that the distribution and dynamics of the investment rate provide identification for capital adjustment costs. Bloom (2009) takes one step further and shows it is possible to distinguish the stochastic process and adjustment costs simultaneously by using moments of investment rate and sales growth rate jointly.

Since the empirical specification in this paper includes two new features-namely unobserved heterogeneities and measurement error, we adopt a similar two-step estimation procedure as in Cooper and Haltiwanger (2006) and use moments for variables in addition to the investment rate for identification. To be specific, this paper finds that for a given Jorgensonian user cost of capital, the profit to sales ratio and log sales to capital ratio could jointly identify the production technology and demand schedule. By pre-estimating the stochastic process in the first step, the distribution and dynamics of investment rate, sales growth rate and log sales to capital ratio could then jointly identify capital adjustment costs, unobserved heterogeneities and measurement error in the second step.

As illustrated in Whited (2010), a necessary and sufficient condition of identification is that the Jacobian matrix $\left[\partial \widehat{\Phi}^{M}(\widehat{\Theta}) / \partial \Theta^{\prime}\right]$ is of full rank. Intuitively, the precision of the estimates is related to the sensitivity of the moments to movements in the structural parameters through this matrix. If the sensitivity is low, the derivative will be near zero, which will produce a high variance for the structural estimates according to equation (18). Therefore, the standard errors of the estimates provide a useful check for local identification.

\subsection{Parameters and Moments}

Column (1) in the upper panel of Table 1 lists the set of parameters $\Theta$ to estimate. In addition to these nine parameters of interest, there are four predetermined parameters. For the Jorgensonian user cost of capital, the main specification imposes $\delta=0.03$, which is the difference between the mean of gross capital growth rate and the sales growth rate; and $r=0.14$, which is the average required rate of return for investment in China estimated in Bai, Hsieh and Qian (2005). 
For the stochastic process, we follow Cooper and Haltiwanger (2006) by estimating the following model in the first step, ${ }^{10}$

$$
\log Y_{i, t}=\alpha+\rho \log Y_{i, t-1}+(1-\bar{\gamma}) \log \widehat{K}_{i, t}-\rho(1-\bar{\gamma}) \log \widehat{K}_{i, t-1}+\eta_{i}+\xi_{i, t}
$$

Our empirical specification on measurement error implies that the idiosyncratic error term $\xi_{i, t}$ is composed of both the innovations of revenue TFP and the measurement error in capital stock,

$$
\xi_{i, t}=\bar{\gamma} e_{i, t}-(1-\bar{\gamma}) e_{i, t}^{K}+\rho(1-\bar{\gamma}) e_{i, t-1}^{K} .
$$

To get a proxy for the variance of $\xi_{i, t}$, we estimate equation (19) and calculate the variance of the first differenced residual $\operatorname{Var}\left(\Delta \widehat{\xi}_{i, t}\right)$. Under the assumption that $e_{i, t}$, $e_{i, t}^{K}$ and $e_{i, t-1}^{K}$ are uncorrelated with each other, this imposes a joint restriction on $\sigma$ and $\sigma_{m e K}$,

$$
\operatorname{Var}\left(\Delta \widehat{\xi}_{i, t}\right)=2\left[\bar{\gamma}^{2} \sigma^{2}+\left(1+\rho+\rho^{2}\right)(1-\bar{\gamma})^{2} \sigma_{m e K}^{2}\right]
$$

By imposing $\rho=0.885$ and $\bar{\gamma}=0.408$ as estimated in Cooper and Haltiwanger (2006), $\sigma$ can be inferred from equation (20) for any estimated $\sigma_{m e K}$ in the second step estimation. A later section considers how sensitive the results are, to imposing different values for $\delta, r$ and $\rho$. In the section of specification tests, we examine the effect of imposing a $\gamma$ which is estimated simultaneously with $\sigma_{m e K}$ in inferring $\sigma$. We also investigate the effect of imposing alternative restriction to equation (20) and estimating $\sigma_{m e K}$ and $\sigma$ simultaneously.

Column (2) in the lower panel of Table 1 lists the set of moments $\widehat{\Phi}^{D}$ to match. The third column reports the value of these empirical moments estimated from the data, whilst the standard errors are reported in the fourth column. The set of moments includes the means, standard deviations, skewness coefficients, serial correlations, and cross correlations between log sales to capital ratio, investment rate, and sales growth rate, in addition to the mean of profit to sales ratio, and proportions of investment spikes, zero investment and disinvestment. The selection of moments is guided by two principles. First, these moments are effective summary statistics for the important features of the data as illustrated in Figures 2 and 3. Second, the properties of the model discussed in Section 2.3 and the empirical specifications discussed in Section 3.2 provide theoretical predictions on how these moments may vary with the structural parameters of our interest, so that jointly this set of moments could potentially identify the parameters listed in the upper panel of Table 1.

\footnotetext{
${ }^{10}$ This equation is derived by taking logs on both sides of the sales equation $Y_{i, t}=\frac{\bar{\gamma} \varepsilon h}{1-\bar{\gamma}} Z_{i, t}^{\bar{\gamma}} \widehat{K}_{i, t}^{1-\bar{\gamma}}$, where $\bar{\gamma}=\frac{1}{N} \sum_{i=1}^{N} \frac{1}{1+\beta_{i}(\varepsilon-1)}$, quasi differencing the logged equation, replacing $\log Z_{i, t}$ and $\rho \log Z_{i, t-1}$ using the $\operatorname{AR}(1)$ structure specified in equation (6), and substituting the observed capital stock with the true capital stock and measurement error specified in Assumption 4.
} 


\section{Empirical Results}

The inverse of the variance-covariance matrix of the empirical moments is estimated using a bootstrapping method. This provides a candidate for the efficient choice of the weighting matrix in the global specification test (17). Michaelides and Ng (2000) find that good finite sample performance requires a simulated sample that is approximately ten times as large as the actual data sample. Therefore $S$ is set as 10 in this empirical exercise. To avoid potential local minima, the minimum quadratic distance problem (16) is solved using the simulated annealing algorithm described in Goffe, Ferrier and Rogers (1994). Alternative starting values for parameters and random draws for TFP shocks have been employed to check the robustness of the results. Within each simulation, the linear homogeneity of the model allows us to detrend the growth rate when solving the model and add back the growth rate in simulating the data. The dynamic programming (7) is solved by the improved policy iteration algorithm (Ljungqvist and Sargent, 1999), taking $\beta_{i}$ and $\mu_{i}$ as state variables in addition to $Z_{t}$ and $K_{t}$. Numerical standard errors for the MSM estimator are calculated according to equation (18). ${ }^{11}$

\subsection{Estimates}

Table 1 presents the empirical results for the benchmark model. Column (4) in the upper panel reports the optimal estimates of the structural parameters and column (5) lists the numerical standard errors of these estimates. All three forms of capital adjustment costs are found to be quantitatively important. In particular, $\widehat{b}_{q}=1.532$ implies a quadratic adjustment cost, which is about $6.5 \%$ of the capital stock, ${ }^{12}$ evaluated at the sample average. $\widehat{b}_{i}=0.370$ suggests that the resale price of capital goods is only $63 \%$ of the purchase price. $\widehat{b}_{f}=0.011$ implies any investment or disinvestment would result in a $1.1 \%$ loss of operating profit. Since about $29.5 \%$ observations are at the inaction region of investment, this implies that on average firms are paying a fixed adjustment cost equal to $0.8 \%$ of their operating profit.

In their comparable specifications, Cooper and Haltiwanger (2006) estimate $\widehat{b}_{q}=$ $0.153, \widehat{b}_{i}=0.019$ and $\widehat{b}_{f}=0.204$; Bloom (2009) finds $\widehat{b}_{q}=0, \widehat{b}_{i}=0.339$ and $\widehat{b}_{f}=0.015$. Therefore compared with similar research using U.S. data, this Chinese dataset has predicted a similar size of $b_{i}$ and $b_{f}$ as in Bloom (2009), a larger $b_{i}$ and a smaller $b_{f}$ than Cooper and Haltiwanger (2006), but a substantially larger $b_{q}$ than both. Nevertheless,

\footnotetext{
${ }^{11} \mathrm{Wu}(2009)$, which is available upon request or via the online Oxford University Library System, provides further technical details.

${ }^{12}$ The size of quadratic adjustment costs as a proportion of capital stock can be calculated as $\frac{b_{q}}{2} E\left(\frac{I_{i . t}}{\bar{K} i, t}\right)^{2}=\frac{b_{q}}{2}\left[\operatorname{Var}\left(\frac{I_{i . t}}{\bar{K} i, t}\right)+\left(E\left(\frac{I_{i . t}}{\bar{K} i, t}\right)\right)^{2}\right]=\frac{1.537}{2}\left(0.256^{2}+0.139^{2}\right)=0.065$.
} 
compared with empirical works inferring quadratic adjustment costs from the ' $Q$ model', for example, Hayashi (1982), where $b_{q}$ is typically estimated to be around 20, the estimate for $b_{q}$ in this paper is in fact much closer to our structural predecessors and is significantly lower than those traditional findings.

The estimated mean and standard deviation for $\log \beta$ implies that capital share $\beta$ varies from 0.021 to 0.329 with a median at 0.082 . The estimates for both the dispersion and the median value of $\beta$ are broadly consistent with those in Jorgenson, Gollop and Fraumeni (1987), who use a production function regression based on U.S. data. ${ }^{13}$ The median value of $\beta$ is even closer to that in Pavcnik (2002), who finds that the average of the capital share in the production function across industries is 0.085 for a large sample of Chilean firms, using consistent Olley and Pakes (1996) structural estimates. The estimate for the demand elasticity with respect to price is $\widehat{\varepsilon}=13.953$. According to equation (4), the profit to sales ratio is determined by $\beta\left(1-\frac{1}{\varepsilon}\right)+\frac{1}{\varepsilon}$ in this model. Therefore, for a given $\beta$, the value of $\varepsilon$ depends on the profitability in the data and is ultimately an empirical question. ${ }^{14}$ Together, the estimates for $\varepsilon$ and heterogeneous $\beta$ imply that the capital coefficient in the sales or profit function $1-\widehat{\gamma}_{i}$ is 0.516 at the median, and varies from 0.210 to 0.810 across the sample.

The estimate for the mean growth rate implies that on average the revenue TFP grows at $8.7 \%$ per year. This is consistent with China's real GDP growth rate in the secondary and tertiary industries at the macro level. Meanwhile, the substantial standard deviation of the growth rate may reflect large ups and downs across heterogeneous firms during economic transition. The standard deviation of the measurement error in capital stock is estimated to be $\widehat{\sigma}_{m e K}=0.522$ and is statistically significant. This suggests that measurement error in capital stock is indeed an important feature of the dataset. According to equation (20), the standard deviation for revenue TFP shocks can be inferred as 0.569 , which measures the level of uncertainty in this model. An estimate of $\widehat{\sigma}=0.569$ is between the baseline level of uncertainty (0.413) and high level of uncertainty (0.826) estimated in Bloom (2009); and at the median $\widehat{\gamma} \widehat{\sigma}=0.275$ is similar to the level of uncertainty (0.30) estimated in Cooper and Haltiwanger (2006). ${ }^{15}$

\footnotetext{
${ }^{13}$ Jorgenson, Gollop and Fraumeni (1987) run production function regression over intermediate input, capital input and labor input and report empirical results for different sectors in their Table 7.3. Among the 45 U.S. manufacturing and services sectors, the capital share estimate varies from 0.0489 (apparel and other fabricated textile products) to 0.404 (communication services) with a median of 0.115 (motor vehicles and equipment). Such estimate for $\beta$ should be distinguished from the one in an aggregate production function for value added with capital and labor inputs only, where Jorgenson, Gollop and Fraumeni (1987) report a capital share of 0.385 for the U.S. in such an aggregate model in their Table 9.8 .

${ }^{14}$ For example, Bond, Söderbom and Wu (2008) find $\varepsilon$ is around 24 for a sample of U.K. manufacturing firms from 1972 to 1991 in the Datastream dataset; Song and $\mathrm{Wu}$ (2013) estimate $\varepsilon$ to be around 10 for a sample of U.S. manufacturing firms from 2002 to 2005 in the Compustat dataset.

${ }^{15}$ Both this paper and Bloom (2009) have assumed a sales function linearly homogeneous in revenue TFP and capital stock such as $Y_{t}=$ constant $\times Z_{t}^{\gamma} \widehat{K}_{t}^{1-\gamma}$. In contrast, the sales function in Cooper and
} 
Column (5) in the lower panel of Table 1 lists the simulated moments from the model evaluated at the optimal estimates. Comparison between columns (5) and (3) implies that the model has provided a reasonably good fit to a large set of empirical moments which describe the level, distribution and dynamics of the key variables.

\subsection{Specification Tests}

Table 2 reports specification tests for alternative models. For reference, the preferred full model is listed in column (1). Columns (2) to (4) show what happens when we impose respectively no quadratic adjustment costs, no irreversibility and no fixed adjustment costs. Compared with the preferred full model, a model with quadratic adjustment costs together with either irreversibility (column (4)) or fixed adjustment costs (column (3)) could fit the data reasonably well. In other words, irreversibility and fixed adjustment costs are two alternative forms of non-convex adjustment costs and are substitutes for one another if we only allow for one of them. In contrast, a model without quadratic adjustment costs (column (2)) fits the data much worse and generates a substantially higher overidentifying restriction test statistic. This is because this restricted model cannot fit the large positive serial correlation in the investment rate. Furthermore, the simulated investment rate series is too volatile, too right-skewed and over-responsive.

Column (5) presents a model which assumes a homogeneous capital share $\beta$. As one may expect, without heterogeneity in $\beta$, the model cannot match the large dispersion and the high serial correlation in log sales to capital ratio. As a result, the model over-estimates adjustment costs, heterogeneity in growth rate and level of uncertainty to match these important features of the data. Column (6) illustrates the result of imposing no heterogeneity in the growth rate $\mu$. Such a model, first, cannot fit the positive serial correlation of the sales growth rate; and second, over-estimates the quadratic adjustment costs. Comparison between columns (5), (6) and (1) therefore highlights the importance of allowing for unobserved heterogeneities in order to get consistent estimates for the adjustment costs.

Column (7) shows the result of imposing no measurement error, which implies $\widehat{\sigma}=1.160$ by equation (20). Not surprisingly, this restricted specification is massively rejected, mainly because the simulated sales growth rates are too volatile at such a high level of uncertainty. To dampen the sales growth rate, the model generates much higher estimates for the adjustment costs, which in turn makes the investment rate too persistent and not dispersed enough compared with the real data. To study the

Haltiwanger (2006) is $Y_{t}=$ constant $\times Z_{t} \widehat{K}_{t}^{1-\gamma}$. All three papers assume a similar law of motion for $Z_{t}$. Therefore the level of uncertainty in our paper is directly comparable with that in Bloom (2009) but should be normalized by $\gamma$ to compare with that in Cooper and Haltiwanger (2006). 
effect of imposing $\bar{\gamma}=0.408$ in the restriction (20), we use $\widehat{\gamma}=\frac{1}{N} \sum_{i=1}^{N} \frac{1}{1+\widehat{\beta}_{i}(\widehat{\varepsilon}-1)}$ which is estimated simultaneously with $\sigma_{m e K}$. Column (8) implies that even greater capital adjustment costs are estimated using this specification. Finally, to examine the effect of using the restriction (20) on the estimates, column (9) reports a model which estimates $\sigma_{m e K}$ and $\sigma$ simultaneously. Instead of using equation (20), the alternative restriction in column (9) assumes that the noise-to-signal ratio is no larger than one, that is $\sigma_{m e K} \leq \sigma$. Such a model estimates even larger measurement error and a higher level of uncertainty.

\subsection{Robustness Tests}

Table 3 presents robustness checks across three different parameters. Column (1) is the benchmark model, where $\delta=0.03, r=0.14$ and $\rho=0.885$. Columns (2) and (3) show the results for the same model but imposing the depreciation rate to be 0.02 and 0.04 respectively. Columns (4) and (5) present the results for the same model but imposing the discount rate to be 0.13 and 0.15 respectively. Compared with the benchmark model, a model with lower depreciation rate or lower discount rate implies slightly higher quadratic adjustment costs and smaller demand elasticity, in order to match the empirical mean of log sales to capital ratio. Nevertheless, with the exception of the estimates for the mean of growth rate $\mu_{\mu}$, the estimates for other parameters are robust to the choice of depreciation rate and discount rate within the range we considered. Columns (6) and (7) show what happens when the same model is estimated but with serial correlation of 0.85 and 0.92 , respectively. As expected, a model imposing higher serial correlation implies less heterogeneity in the growth rate. However, there is no significant difference between estimates reported in these two columns and the estimates in the benchmark model.

\subsection{Subsample Results}

Table 4 estimates the same model on several subsamples. We estimate $\operatorname{Var}\left(\Delta \widehat{\xi}_{i, t}\right)$ for each subsample in the first-step, and impose different values of $\delta$ and $r$, searching along a range of potential values to match each subsample best. These values are reported in the corresponding columns at the bottom of Table 4, together with the number of firms and the median number of employees.

The first sample split is between manufacturing firms and services firms. According to columns (1) and (2), firms in the service sector are more profitable and grow faster on average, however they also face higher quadratic and fixed adjustment costs than their manufacturing counterparts. This could imply that the investment climate of the service sector is worse than that of the manufacturing sector in China. However this 
could also be driven by the fact that firms in the service sector are on average much smaller than those in the manufacturing sector.

To study whether there is a significant difference between large and small firms in terms of their adjustment costs, we split the sample at the median number of employees and estimate the model for large firms in column (3) and small firms in column (4). To take into account that the data for large firms might be consolidated across several small subplants within the firm, following Bloom (2009) we assume that the large firms have been aggregated over 3 small subplants, given their median number of employees is three times as large as that of the whole sample.

The empirical results indicate that in terms of non-convex adjustment costs, large firms face a combination of larger irreversibility and smaller fixed adjustment costs, while small firms face the opposite combination. However, in terms of convex adjustment costs, the estimate for large firms is substantially lower than that of the small firms. If one thinks irreversibility and fixed adjustment costs are two alternative forms of non-convex adjustment costs, the significant difference in the quadratic adjustment costs implies that larger firms face much smaller investment frictions. This finding is consistent with the conventional observation that in developing countries large firms have a more favorable investment climate than small firms, as is well documented in Tybout (2000).

To further examine whether differences in capital adjustment costs are informative about the investment environments, we report empirical results for firms in Beijing and Shanghai in column (5) and firms in Guiyang and Lanzhou in column (6). The subnational Doing Business survey on China has highlighted substantial variation in the ease of doing business across geographic regions. Cities in eastern coastal area (such as Beijing and Shanghai) are much more advanced than cities in western inland area (such as Guiyang and Lanzhou), with respect to their financial development, investment infrastructure, and business regulations among others. Therefore one would expect a much better investment climate in Beijing and Shanghai, compared with that in Guiyang and Lanzhou.

The estimates for these two subsamples are indeed consistent with this prior belief. With similar size of irreversibility, the estimates for both quadratic and fixed adjustment costs are substantially larger for firms in Guiyang and Lanzhou than for firms in Beijing and Shanghai. On average, firms in Guiyang and Lanzhou are paying a quadratic adjustment cost which is $9.43 \%$ of their capital stock and a fixed adjustment cost which is $2.6 \%$ of their operating profit. In contrast, the corresponding cost proportions are only $2.8 \%$ and $0.48 \%$ for firms in Beijing and Shanghai. 


\subsection{Counterfactual Simulations}

The estimated structural model provides a useful framework to quantify the effects of adjustment costs on forgone aggregate output. Table 5.1 simulates these effects for the whole sample according to equation (12). Recall that there are heterogeneities in both $\beta$ and $\mu$, and the heterogeneity in $\beta$ implies the heterogeneity in $\gamma$ by equation (3). These effects are therefore simulated for different types of firms along $1-\gamma$, the capital coefficient in the sales or profit function, and $\mu$, the growth rate of the revenue TFP.

On average the actual aggregate capital stock is $61.3 \%$ lower than the frictionless level. Given that on average the log capital stock counts for $51.2 \%$ in the log output, the actual aggregate output is $31.4 \%$ lower than the frictionless benchmark. Across different types of firms, for a given level of growth rate, the losses in aggregate capital stock increase with the capital coefficient. For a given level of capital coefficient, the losses in aggregate capital stock increase with the growth rate. Both of them are consistent with the economic intuition implied by the investment model.

To further study the relative importance of different forms of adjustment costs, Table 5.2 reports the average losses across different types of firms when there are only quadratic adjustment costs, irreversibility and fixed adjustment costs, respectively. As highlighted in Table 5.2, although irreversibility and fixed adjustment costs also generate a sizeable loss, it is the presence of the quadratic adjustment costs that contributes most to the losses, as is seen in Table 5.1. To check the validity of the first-order approximation derived in section 2.5, consider firms which have a median level of $\gamma$ and $\mu$. Since the average investment rate is 0.151 and $b_{q}$ is estimated at 1.532 for the full sample, equation (15) predicts an aggregate output loss of around 0.225. This is very close to the magnitude simulated in the $5^{\text {th }}$ row of Table 5.1. Recall from the specification tests, had we not allowed for unobserved heterogeneities or measurement error, the model would have estimated even larger quadratic adjustment costs, and hence even more substantial losses.

Taking the estimated structural model as a laboratory, controlled experiments can be conducted to investigate hypothetical questions. For example, how would the aggregate output losses differ, if Chinese firms faced the same level of frictions as U.S. firms? Table 5.3 thus simulates the effects of adjustment costs for China by imposing its $b_{q}, b_{i}$ and $b_{f}$ to be the corresponding values estimated from Bloom (2009), keeping all other factors constant. Table 5.4 reports gains from the improvement by comparing the quantitative effects in Table 5.1 with those in Table 5.3. Averaging across different types of firms, a reduction in frictions down to the U.S. level would generate a $25.2 \%$ increase in China's aggregate output.

Tables 5.5 and 5.6 report the gains for small firms and firms located in Guiyang 
and Lanzhou, using large firms and firms in Beijing and Shanghai respectively as a benchmark. Within China, if the small firms had operated in a better environment as implied by the lower level of adjustment costs faced by their large counterparts, their aggregate output would be $34.2 \%$ higher. Aggregate output gain would also be substantial, as large as $24.8 \%$, had firms in Guiyang and Lanzhou faced the lower frictions that their counterparts in Beijing and Shanghai enjoyed.

\section{Conclusion and Discussion}

Over the past decade, China has been consistently ranked only around $90^{\text {th }}$ out of 180 economies in terms of the overall ease of doing business (World Bank, 2007). Even within China, the ease of doing business varies greatly across cities (World Bank, 2008). Using an investment-capital adjustment costs framework, this paper indirectly infers the aggregate output loss in China caused by a poor investment climate. The estimated substantial output gain by improving the investment climate to the U.S. benchmark gives a quantitative measure of "how bad the investment climate is in China". The subsample estimates also find much higher quadratic adjustment costs in cities with lower Doing Business ranking than those with higher ranking. Although investment frictions and capital adjustment costs are abstract and not observable directly, the Doing Business ranking is constructed based on specific indicators and is easily available. Therefore, the consistency between the estimates of capital adjustment costs and the Doing Business ranking implies the importance of improving lagged indicators identified in the Doing Business ranking in order to reduce aggregate output loss.

Although this empirical exercise quantifies the significant effects of investment frictions on aggregate output loss, there are some limitations that need further investigation. First, instead of making a one-to-one correspondence between capital adjustment costs and the specific factors in the Doing Business ranking, this paper takes capital adjustment costs as a generic representation of various investment frictions, so as to quantify their overall effects. This complements other researches which aim to give more detailed policy advice, by estimating the impact of particular frictions. For example, Bond, Söderbom and Wu (2007) study how costly external finance may affect capital accumulation for firms in Brazil and China.

Second, there has been a recent debate in the development and economic growth literature, for example, Easterly and Levine (2001), on whether it is factor accumulation or TFP that is more important for economic growth. The finding of this paper is in line with a vast literature emphasizing the importance of capital accumulation, for China as in Ding and Knight (2011) and for many economies in general as in Bond, Leblebicioglu, and Schiantarelli (2010). However, this does not necessarily imply the 
insignificance of TFP. The high growth rate of revenue TFP estimated from the model is taken as exogenous in this paper. Estimating an investment model with endogenous TFP growth will be an interesting task for future research.

Finally, like most researches on capital adjustment costs, the analysis in this paper is partial equilibrium in nature. Therefore the magnitudes estimated in this paper are subject to potential general equilibrium effects. To fully address the aggregate output loss in a general equilibrium framework, one has to develop a dynamic stochastic general equilibrium model to reflect the complex interaction between TFP shocks, endogenous factor prices and capital adjustment dynamics. Furthermore, the choice of production technology may be endogenous and the market structure may evolve in a more general setup. Such analysis is certainly important but is beyond the scope of this paper. 


\section{References}

[1] ABel, Andrew B. (1983), "Optimal Investment Under Uncertainty", American Economic Review, 73, 228-233.

[2] Abel, Andrew B. and Eberly, Janice C. (1994), "A Unified Model of Investment Under Uncertainty", American Economic Review, 84, 1369-1384.

[3] Abel, Andrew B. and Eberly, Janice C. (1999), "The Effects of Irreversibility and Uncertainty on Capital Accumulation", Journal of Monetary Economics, 44, 339-377.

[4] Ackerberg, Daniel, Lanier Benkard, C., Berry, Steven and Pakes, Ariel (2007), "Econometric Tools for Analyzing Market Outcomes", Handbook of Econometrics, in: J.J. Heckman \& E.E. Leamer (ed.), edition 1, volume 6, chapter 63, Elsevier.

[5] Bai, Chong-En, Hsien, Chang-Tai and Qian, Yingyi (2006), "The Returns to Capital in China", Brookings Papers on Economic Activity, 37, 61-102.

[6] BanerJee, Abhijit V. and Duflo, Esther (2005), "Growth Theory through the Lens of Development Economics", in: Philippe Aghion \& Steven Durlauf (ed.), Handbook of Economic Growth, edition 1, volume 1, chapter 7, 473-552.

[7] Bloom, Nick (2000), "The Dynamic Effects of Real Options and Irreversibility on Investment and Labour Demand", Institute for Fiscal Studies Working Paper No.W00/15.

[8] BLoom, Nick (2009), "The Impact of Uncertainty Shocks", Econometrica, 77, 623-685.

[9] Blundell, Richard and Bond, Stephen R. (2000), "GMM Estimation with Persistent Panel Data: An Application to Production Functions", Econometric Reviews, 19, 321-340.

[10] Bond, Stephen R., Leblebicioglu, Asli and Schiantarelli, Fabio (2010), "Capital Accumulation and Growth: A New Look at the Empirical Evidence", Journal of Applied Econometrics, 25, 1073-1099.

[11] Bond, Stephen R., Soderbom, Måns and Wu, Guiying (2007), "Investment and Financial Constraints: Empirical Evidence for Firms in Brazil and China", Mimeo, Department of Economics, University of Oxford.

[12] Bond, Stephen R., Soderbom, Måns and Wu, Guiying (2008), "A Structural Estimation for the Effects of Uncertainty on Capital Accumulation with Heterogeneous Firms", Mimeo, Department of Economics, University of Oxford.

[13] Bond, Stephen R., Soderbom, Måns and Wu, Guiying (2011), "Pursuing the wrong options? Adjustment costs and the relationship between uncertainty and capital accumulation", Economics Letters, 111, 249-251.

[14] Browning, Martin, Ejrnaes, Mette and Alvarez, Javier (2010), "Modelling Income Dynamics with Lots of Heterogeneity", Review of Economic Studies, 77, 1353-1381.

[15] Chirinko, Robert S. (1993), "Business Fixed Investment Spending: A Critical Survey of Modelling Strategies, Empirical Results, and Policy Implications", Journal of Economic Literature, 31, 1875-1911. 
[16] Cooper, Russell W. and Ejarque, João (2003), "Financial Frictions and Investment: A Requiem in Q", Review of Economic Dynamics, 6, 710-728.

[17] Cooper, Russell W., Gong, Guan, and Yan, Ping (2011), "Dynamic Labor Demand in China: Public and Private Objectives", NBER Working Paper, No. 16498.

[18] Cooper, Russell W. and Haltiwanger, John (2006), "On the Nature of Capital Adjustment Costs", Review of Economic Studies, 73, 611-634.

[19] Dixit, Avinash K. and Pindyck, Robert S. (1994), Investment Under Uncertainty. Princeton University Press, Princeton, NJ.

[20] Doms, Mark and Dunne, Timothy (1998), "Capital Adjustment Patterns in Manufacturing Plants", Review of Economic Studies, 67, 117-145.

[21] Ding, Sai and Knight, John (2011), "Why has China Grown So Fast? The Role of Physical and Human Capital Formation", Oxford Bulletin of Economics and Statistics, 73, 141-174.

[22] Easterly, William and Levine, Ross (2001), "What Have We Learned from a Decade of Empirical Research on Growth? It's Not Factor Accumulation: Stylized Facts and Growth Models", the World Bank Economic Review, 15, 177-219.

[23] Eberly, Janice C., Rebelo, Sergio, and Vincent, Nicolas (2008), "Investment and Value: A Neoclassical Benchmark", NBER Working Paper, No. 13866.

[24] Eckstein, Zvi and Wolpin, Kenneth I. (1999), "Why Youths Drop Out of High School: The Impact of Preferences, Opportunities, and Abilities", Econometrica, 67, 1295-1339.

[25] Fafchamps, Marcel and Soderbom, Måns (2006), "Wages and Labor Management in African Manufacturing", Journal of Human Resources, 41, 346-379.

[26] Foster, Lucia, Haltiwanger, John, and Syverson, Chad (2008), "Reallocation, Firm Turnover, and Efficiency: Selection on Productivity or Profitability?" American Economic Review, 98, 394-425.

[27] Goffe, William L., Ferrier, Gary D. and Rogers, John (1994), "Global Optimization of Statistical Functions with Simulated Annealing", Journal of Econometrics, 60, 65-99.

[28] Gouriéroux, Christian and Monfort, Alain (1996), Simulation-Based Econometric Methods, Oxford University Press.

[29] Hamermesh, Daniel S. and Pfann, Gerard A. (1996), "Adjustment Costs in Factor Demand, Journal of Economic Literature, 34, 1264-1292.

[30] Hayashi, Fumio, (1982), "Tobin's Marginal q and Average q: A Neoclassical Interpretation", Econometrica, 50, 213-224.

[31] Hennessy, Christopher A. and Whited, Toni M. (2007), "How Costly is External Financing? Evidence from a Structural Estimation", Journal of Finance, 62, 1705-1745.

[32] Jorgenson, Dale W., Gollop, Frank M. and Fraumeni, Barbara M. (1987), Productivity and U.S Economic Growth, toExcel Press.

[33] Khan, Aubhik and Thomas, Julia K. (2006), "Adjustment Costs", The New Palgrave Dictionary of Economics, Palgrave Macmillan. 
[34] Luungqvist, Lars and Sargent, Thomas (2000), Recursive Macroeconomic Theory, MIT Press.

[35] Michaelides, Alexander and NG, Serena (2000), "Estimating the rational expectations model of speculative storage: A Monte Carlo comparison of three simulation estimators", Journal of Econometrics, 96, 231-266.

[36] Olley, G. Steven, and Pakes, Ariel (1996), "The Dynamics of Productivity in the Telecommunications Equipment Industry", Econometrica, 64, 1263-1297.

[37] Pavcnik, Nina (2002), "Trade Liberalization, Exit, and Productivity Improvement: Evidence from Chilean Plants", Review of Economic Studies, 69, 245-276.

[38] SchÜndeln, Matthias (2006), "Modeling Firm Dynamics to Identify the Cost of Financing Constraints in Ghanaian Manufacturing", Working Paper, Department of Economics, Havard University.

[39] Soderbom, Måns and Teal, Francis (2004), "Size and Efficiency in African Manufacturing Firms: Evidence from Firm-Level Panel Data", Journal of Development Economics, 73, 369-394.

[40] Song, Zheng, Storesletten, Kjetil and Zilibotti, Fabrizio (2011), "Growing Like China", American Economic Review, 101, 202-241.

[41] Song, Zheng, and Wu, Guiying (2013), "A Structural Estimation on Capital Misallocation in Chinese Manufacturing", Mimeo, Booth School of Business, University of Chicago.

[42] Tyвout, James R. (2000), "Manufacturing Firms in Developing Countries: How Well Do They Do, and Why?" Journal of Economic Literature, 38, 11-44.

[43] Whited, Toni (2010), "Structural Estimation", lecture on structural estimation at the 2010 FMA.

[44] World Bank (2005), A Better Investment Climate for Everyone, World Development Report 2005, the World Bank and Oxford University Press.

[45] World Bank (2007), Doing Business 200\%: How to Reform? the World Bank and the International Finance Corporation.

[46] World Bank (2008), Doing Business in China 2008, the World Bank and the Social Sciences Academic Press of China.

[47] Wu, Guiying (2009), Uncertainty, Investment and Capital Accumulation: A Structural Econometric Approach, D.Phil. Thesis, University of Oxford. 


\section{Appendix 1: Selected Indicators for the Doing Business Ranking}

\begin{tabular}{l|c|c|c|c}
\hline & \multirow{2}{*}{ U.S. } & \multicolumn{3}{c}{ China } \\
\cline { 3 - 5 } & & national & $\begin{array}{c}\text { Beijing/ } \\
\text { Shanghai }\end{array}$ & $\begin{array}{c}\text { Guiyang/ } \\
\text { Lanzhou }\end{array}$ \\
\hline Starting a business & & 35 & $37 / 35$ & $50 / 47$ \\
\hline Days to open a business (days) & 5 & 9.3 & $3.2 / 3.1$ & $26.6 / 14.1$ \\
\hline Cost to open a business (\% of income per capita) & 0.7 & \multicolumn{3}{l}{} \\
\hline Registering property & 12 & 32 & $59 / 29$ & $77 / 78$ \\
\hline Days to register property (days) & 0.5 & 3.1 & $3.1 / 3.6$ & $12.6 / 7.8$ \\
\hline Cost to register property (\% of property value) & 7 & 2 & n.a. & n.a. \\
\hline Getting credit & 6 & 4 & n.a. & n.a. \\
\hline Strength of legal rights index (0-10) & n.a. & n.a. & $15 / 8$ & $17 / 20$ \\
\hline Depth of credit information index (0-6) & n.a. & n.a. & $2.7 / 2.9$ & $6.9 / 8$ \\
\hline Days to create and register collateral (days) & & & \\
\hline Cost to create and register collateral (\% of loan value) & & & \\
\hline Enforcing contract & 300 & 292 & $340 / 292$ & $397 / 440$ \\
\hline Days to enforce contracts (days) & 7.7 & 26.8 & $9.6 / 9$ & $23 / 29.9$ \\
\hline Cost to enforce contracts (\% of claim value)
\end{tabular}

Note:

1. The data for U.S. and China national level are from pages 150 and 105 of World Bank (2007). And the data for cities Beijing, Shanghai, Guiyang and Lanzhou are from pages 38 and 39 of World Bank (2008). See website: www.doingbusiness.org for more information on the Doing Business ranking.

2. n.a. = not applicable. The time and cost of registering collateral were not reported in the global Doing Business study. The strength of legal rights index and depth of credit information were not reported in the Doing Business in China 2008. 


\section{Appendix 2: Data}

\section{Sampling}

The Chinese dataset used in this paper was collected in year 2001 and 2003 under the Investment Climate Surveys by the World Bank. These surveys cover more than 26,000 firms in 53 developing countries, and aim to understand how investment climates vary around the world and how they influence growth and poverty. The sample of firms in each country is stratified by size, sector and location.

The original Chinese samples provide annual observations for up to 3 years in the period 1998-2000 for 1548 firms distributed across 5 cities (Beijing, Chengdu, Guangzhou, Shanghai and Tianjin), and in the period 2000-2002 for 2400 firms distributed across 18 cities (Dalian, Benxi, Changchun, Ha'erbin, Hangzhou, Wenzhou, Nanchang, Zhengzhou, Wuhan, Changsha, Shenzhen, Jiangmen, Nanning, Chongqing, Guiyang, Kunming, Xi'an and Lanzhou). Overall these 3948 firms were distributed across 10 manufacturing industries (auto and auto parts, biotech products and Chinese medicine, electronic equipment, chemical products and medicine, electronic parts making, food processing, garment and leather products, household electronics, metallurgical products, and transportation equip) and 4 services industries (accounting and non-banking financial service, advertisement and marketing, business services, and information technology).

\section{Data Cleaning}

Firms with number of permanent employees less than 10 or larger than 1000 are dropped to rule out extremely small or large observations. Using information from China Statistical Yearbook, we then deflate investment and capital stock data using province-specific price indices of investment in fixed assets and deflate profit and sales data using province-specific ex-factory price indices of industrial products. After calculating the five key variables in ratio or growth rate according to definition in Section 3.1, we trim the top and bottom 5\% observations to rule out extreme values. The final sample used for estimation is a three-year panel of 3618 firms, with median number of employees 112.

\section{Macroeconomic Background over Sample Period}

Table A. Macroeconomic Indicators for China: 1998-2002 (\%)

\begin{tabular}{l|r|r|r|r|r}
\hline & 1998 & 1999 & 2000 & 2001 & 2002 \\
\hline GDP (PPP) share of world total & 10.2 & 10.6 & 10.9 & 11.5 & 12.1 \\
\hline real GDP growth rate (secondary industry) & 8.9 & 8.1 & 9.4 & 8.4 & 9.8 \\
\hline real GDP growth rate (tertiary industry) & 8.3 & 7.7 & 8.1 & 8.4 & 7.5 \\
\hline inflation rate, GDP deflator & -0.8 & -1.4 & 0.4 & 0.7 & -0.8 \\
\hline fixed capital formation as share of GDP & 37.1 & 36.7 & 35.1 & 36.3 & 37.9 \\
\hline
\end{tabular}

Sources: World Economic Outlook, IMF; World Development Indicator, World Bank; China Statistical Yearbook; National Bureau of Statistics of China. 


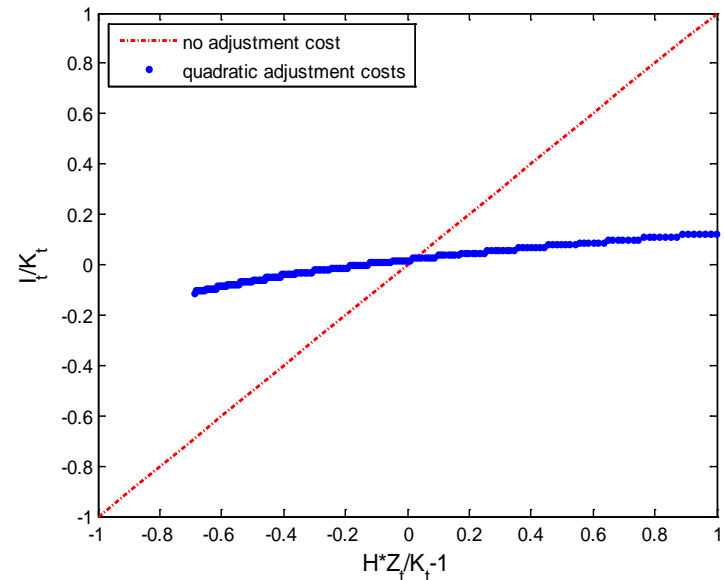

Figure 1a: Investment Policy for Quadratic Adjustment Costs

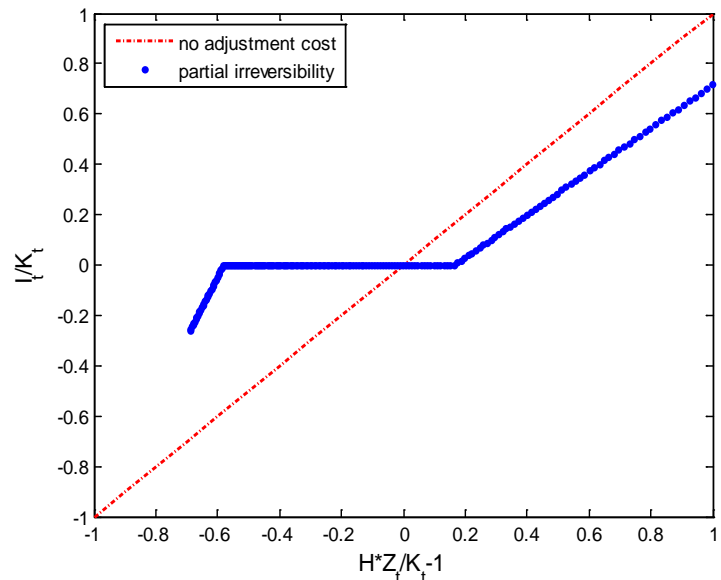

Figure 1b: Investment Policy for Irreversibility

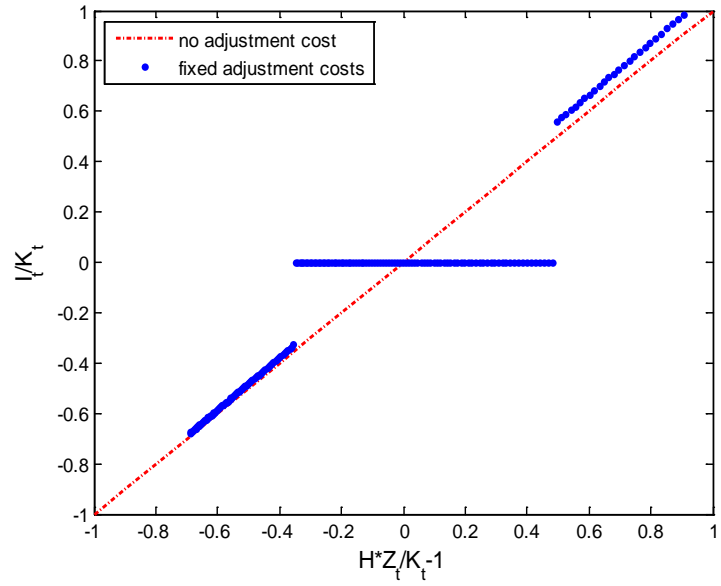

Figure 1c: Investment Policy for Fixed Adjustment Costs 


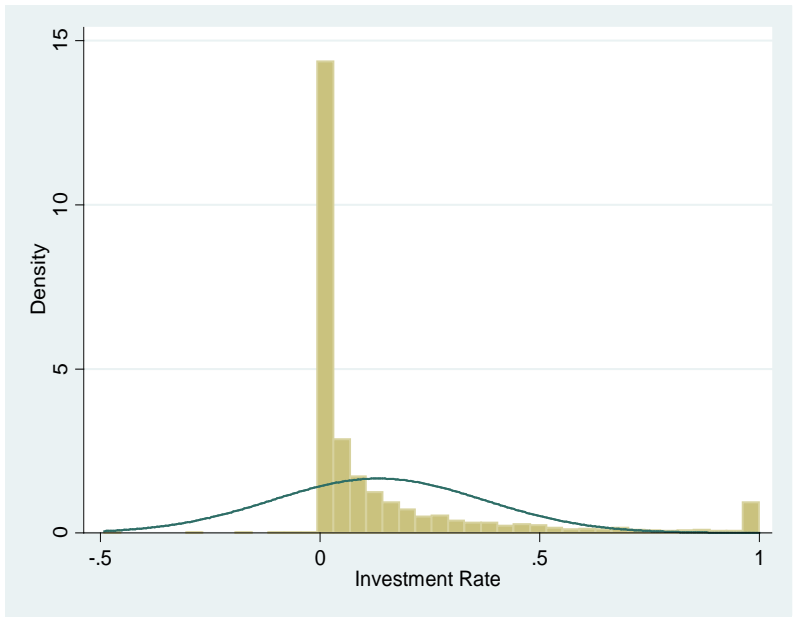

Figure 2a: Empirical Distribution for Investment Rate

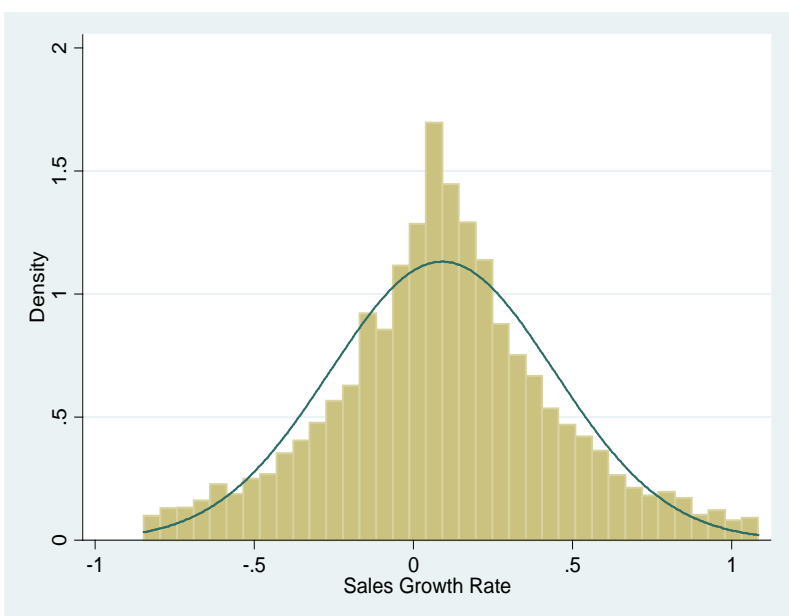

Figure 2b: Empirical Distribution for Sales Growth Rate

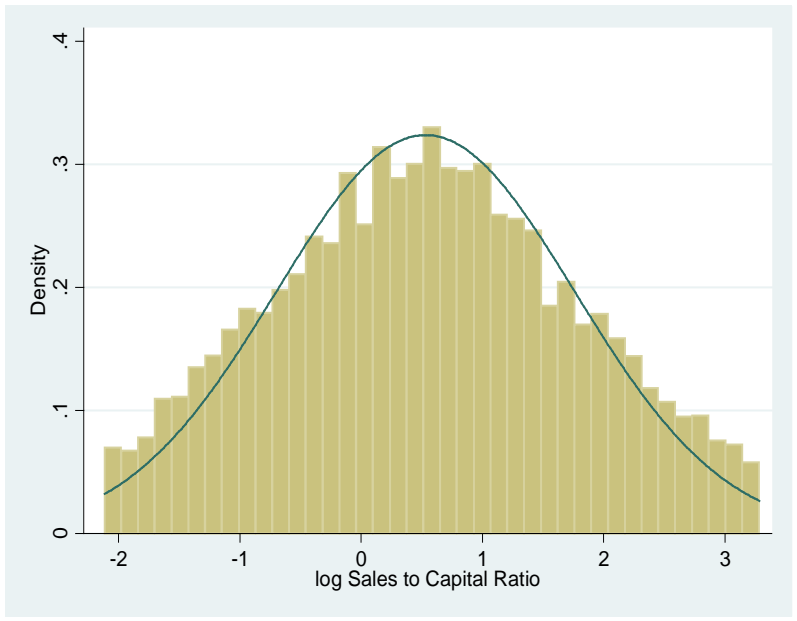

Figure 2c: Empirical Distribution for Capital Intensity

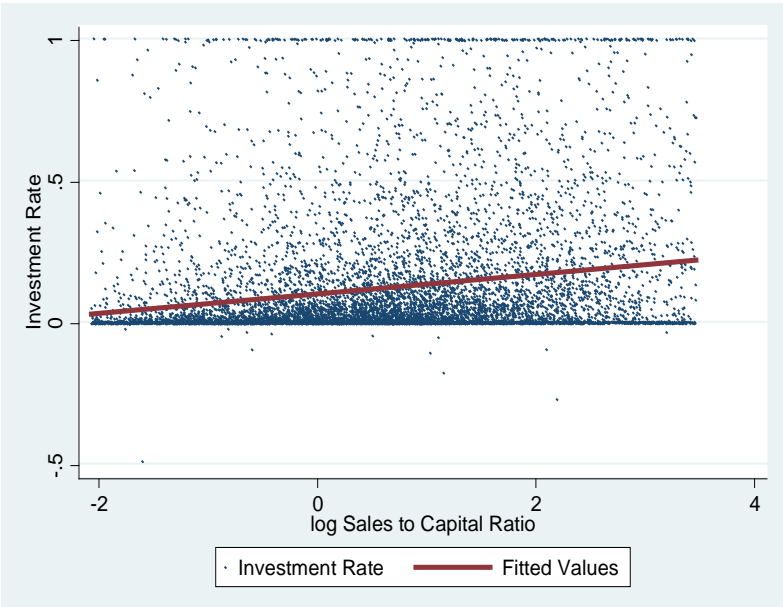

Figure 3a: Investment Rate versus proxy for MRPK

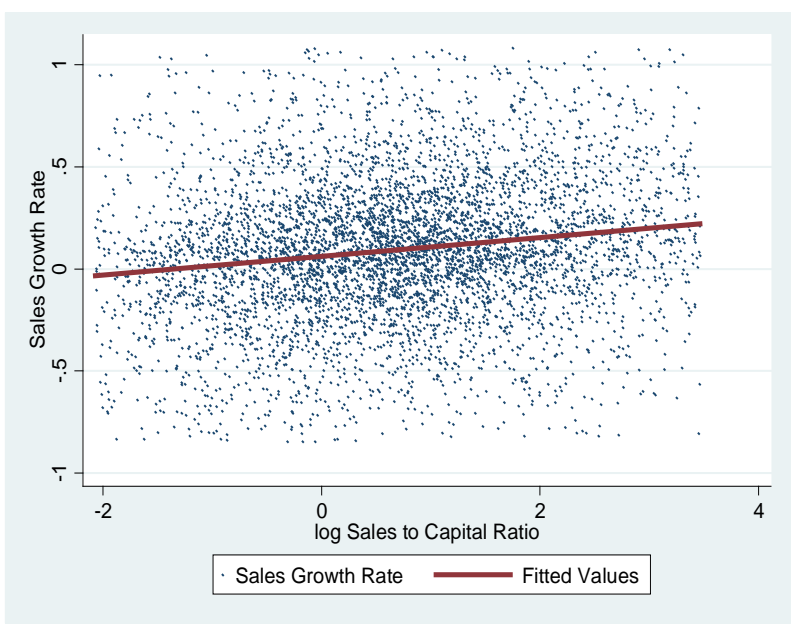

Figure 3b: Sales Growth Rate versus proxy for MRPK

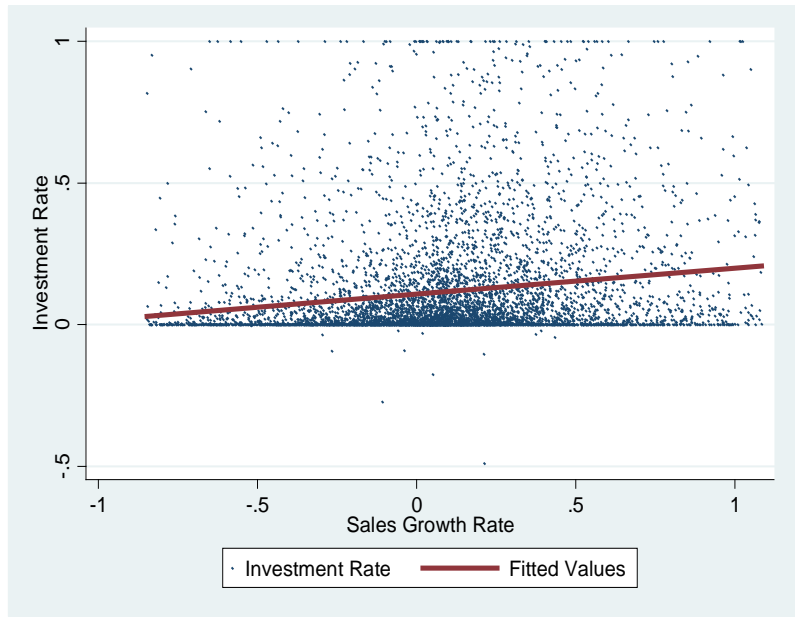

Figure 3c: Investment Rate versus Sales Growth Rate 
Table 1. Empirical Results

\begin{tabular}{|c|c|c|c|c|}
\hline $\operatorname{col}(1)$ & $\operatorname{col}(2)$ & $\operatorname{col}(3)$ & $\operatorname{col}(4)$ & $\operatorname{col}(5)$ \\
\hline Definition for Parameters & Parameters & & Estimate & s.e. \\
\hline quadratic adjustment costs & $\overline{b_{q}}$ & & 1.532 & 0.122 \\
\hline irreversibility & $b_{i}$ & & 0.370 & 0.082 \\
\hline fixed adjustment costs & $b_{f}$ & & 0.011 & 0.005 \\
\hline demand elasticity & $\varepsilon$ & & 13.953 & 0.892 \\
\hline mean of log capital share & $\mu_{\log \beta}$ & & -2.498 & 0.022 \\
\hline std. dev. of log capital share & $\sigma_{\log \beta}$ & & 1.386 & 0.017 \\
\hline mean of growth rate & $\mu_{\mu}$ & & 0.087 & 0.001 \\
\hline std. dev. of growth rate & $\sigma_{\mu}$ & & 0.089 & 0.005 \\
\hline std. dev. of measurement errors & $\sigma_{\text {meK }}$ & & 0.522 & 0.003 \\
\hline std. dev. of TFPR shocks (inferred) & $\sigma$ & & 0.569 & \\
\hline$\overline{\text { Definition for Moments }}$ & Moments & Empirical & $\overline{\text { s.e. }}$ & Simulated \\
\hline mean of profit to sales ratio & $\operatorname{mean}(\pi / \mathrm{Y})$ & 0.211 & 0.002 & 0.218 \\
\hline mean of capital intensity & mean $(\log (\mathrm{Y} /$ Khat $))$ & 0.533 & 0.020 & 0.554 \\
\hline mean of invetment rate & mean $(\mathrm{I} / \mathrm{K})$ & 0.139 & 0.003 & 0.151 \\
\hline mean of sales growth rate & $\operatorname{mean}(\Delta \log Y)$ & 0.092 & 0.005 & 0.088 \\
\hline std. dev. of capital intensity & $\operatorname{sd}(\log (\mathrm{Y} / \mathrm{Khat}))$ & 1.233 & 0.011 & 1.278 \\
\hline std. dev. of invetment rate & $\operatorname{sd}(\mathrm{I} / \mathrm{K})$ & 0.256 & 0.005 & 0.190 \\
\hline std. dev. of sales growth rate & $\operatorname{sd}(\Delta \log Y)$ & 0.353 & 0.004 & 0.338 \\
\hline skewness of capital intensity & skew $(\log (\mathrm{Y} /$ Khat $))$ & 0.042 & 0.023 & 0.189 \\
\hline skewness of invetment rate & skew $(\mathrm{I} / \mathrm{K})$ & 2.540 & 0.065 & 2.553 \\
\hline skewness of sales growth rate & skew $(\mathrm{d} \log \mathrm{Y})$ & 0.052 & 0.027 & 0.048 \\
\hline serial correlation of capital intensity & $\operatorname{scorr}(\log (\mathrm{Y} /$ Khat $))$ & 0.852 & 0.006 & 0.843 \\
\hline serial correlation of invetment rate & $\operatorname{scorr}(\mathrm{I} / \mathrm{K})$ & 0.428 & 0.021 & 0.492 \\
\hline serial correlation of sales growth rate & $\operatorname{scorr}(\Delta \log Y)$ & 0.078 & 0.023 & 0.014 \\
\hline how investment rate responds to MRPK & $\operatorname{corr}(\mathrm{I} / \mathrm{K}, \log (\mathrm{Y} / \mathrm{K}))$ & 0.191 & 0.012 & 0.407 \\
\hline how sales growth rate responds to MRPK & $\operatorname{corr}(\Delta \log \mathrm{Y}, \log (\mathrm{Y} / \mathrm{K}))$ & 0.163 & 0.014 & 0.213 \\
\hline how investment rate responds to sales growth & $\operatorname{corr}(\mathrm{I} / \mathrm{K}, \Delta \log \mathrm{Y})$ & 0.159 & 0.013 & 0.446 \\
\hline proportion of investment spikes & $\operatorname{Prop}(\mathrm{I} / \mathrm{K}>0.2)$ & 0.253 & 0.006 & 0.286 \\
\hline proportion of investment inaction & $\operatorname{Prop}(\mathrm{I} / \mathrm{K}=0)$ & 0.295 & 0.006 & 0.289 \\
\hline proportion of disinvestment & $\operatorname{Prop}(\mathrm{I} / \mathrm{K}<0)$ & 0.002 & 0.000 & 0.002 \\
\hline over-identifying restriction test stati & $\overline{\mathrm{OI}}$ & & & 1051 \\
\hline
\end{tabular}


Table 2. Specification Tests

\begin{tabular}{|c|c|c|c|c|c|c|c|c|c|}
\hline Parameters & $\begin{array}{r}\text { col (1) } \\
\text { full }\end{array}$ & $\begin{array}{r}\operatorname{col}(2) \\
b_{q}=0\end{array}$ & $\begin{array}{c}\operatorname{col}(3) \\
b_{i}=0\end{array}$ & $\begin{array}{l}\operatorname{col}(4) \\
b_{f}=0\end{array}$ & $\begin{array}{r}\operatorname{col}(5) \\
\sigma_{\log \beta}=0\end{array}$ & $\begin{array}{l}\operatorname{col}(6) \\
\sigma_{\mu}=0\end{array}$ & $\begin{array}{r}\operatorname{col}(7) \\
\sigma_{m e K}=0\end{array}$ & $\begin{array}{c}\text { col (8) } \\
\text { free } \gamma\end{array}$ & $\begin{array}{c}\text { col (9) } \\
\text { free } \sigma\end{array}$ \\
\hline$b_{q}$ & 1.532 & 0.000 & 1.964 & 1.142 & 3.405 & 1.730 & 2.592 & 2.121 & 2.623 \\
\hline$b_{i}$ & 0.370 & 0.211 & 0.000 & 0.428 & 0.295 & 0.236 & 0.446 & 0.282 & 0.248 \\
\hline$b_{f}$ & 0.011 & 0.000 & 0.077 & 0.000 & 0.019 & 0.060 & 0.045 & 0.029 & 0.047 \\
\hline$\varepsilon$ & 13.953 & 10.164 & 15.459 & 13.591 & 13.509 & 17.657 & 24.980 & 15.099 & 18.376 \\
\hline$\mu_{\log \beta}$ & -2.498 & -2.496 & -2.448 & -2.494 & -2.345 & -2.387 & -2.201 & -2.484 & -2.446 \\
\hline$\sigma_{\log \beta}$ & 1.386 & 1.265 & 1.346 & 1.376 & 0.000 & 1.381 & 1.263 & 1.350 & 1.393 \\
\hline$\mu_{\mu}$ & 0.087 & 0.091 & 0.086 & 0.090 & 0.089 & 0.090 & 0.082 & 0.088 & 0.089 \\
\hline$\sigma_{\mu}$ & 0.089 & 0.000 & 0.044 & 0.092 & 0.141 & 0.000 & 0.063 & 0.089 & 0.087 \\
\hline$\sigma_{m e K}$ & 0.522 & 0.580 & 0.517 & 0.525 & 0.500 & 0.494 & 0.000 & 0.546 & 0.595 \\
\hline$\sigma$ & 0.569 & 0.285 & 0.585 & 0.555 & 0.639 & 0.655 & 1.160 & 0.580 & 0.629 \\
\hline \multicolumn{10}{|l|}{ Simulated Moments } \\
\hline $\operatorname{mean}(\pi / Y)$ & 0.218 & 0.227 & 0.215 & 0.218 & 0.163 & 0.222 & 0.225 & 0.211 & 0.213 \\
\hline mean $(\log (\mathrm{Y} /$ Khat $))$ & 0.554 & 0.657 & 0.712 & 0.509 & 0.433 & 0.607 & 0.171 & 0.602 & 0.600 \\
\hline $\operatorname{mean}(\mathrm{I} / \mathrm{K})$ & 0.151 & 0.171 & 0.148 & 0.156 & 0.168 & 0.153 & 0.122 & 0.152 & 0.157 \\
\hline $\operatorname{mean}(\Delta \log Y)$ & 0.088 & 0.091 & 0.086 & 0.091 & 0.095 & 0.091 & 0.080 & 0.088 & 0.088 \\
\hline $\operatorname{sd}(\log (Y /$ Khat $))$ & 1.278 & 1.238 & 1.272 & 1.261 & 1.047 & 1.277 & 1.064 & 1.267 & 1.311 \\
\hline $\operatorname{sd}(\mathrm{I} / \mathrm{K})$ & 0.190 & 0.310 & 0.181 & 0.204 & 0.200 & 0.182 & 0.131 & 0.189 & 0.199 \\
\hline $\operatorname{sd}(\Delta \log Y)$ & 0.338 & 0.213 & 0.330 & 0.332 & 0.320 & 0.349 & 0.472 & 0.333 & 0.334 \\
\hline skew $(\log (\mathrm{Y} /$ Khat $))$ & 0.189 & 0.005 & 0.155 & 0.172 & -0.249 & 0.166 & 0.641 & 0.190 & 0.188 \\
\hline skew(I/K) & 2.553 & 4.223 & 2.394 & 2.768 & 1.838 & 2.369 & 1.277 & 2.529 & 2.795 \\
\hline $\operatorname{skew}(\mathrm{d} \log \mathrm{Y})$ & 0.048 & 0.461 & 0.049 & 0.062 & 0.025 & 0.059 & 0.077 & 0.043 & 0.050 \\
\hline $\operatorname{scorr}(\log (\mathrm{Y} /$ Khat $))$ & 0.843 & 0.817 & 0.846 & 0.839 & 0.786 & 0.857 & 0.921 & 0.827 & 0.813 \\
\hline $\operatorname{scorr}(\mathrm{I} / \mathrm{K})$ & 0.492 & 0.091 & 0.360 & 0.484 & 0.592 & 0.345 & 0.740 & 0.474 & 0.432 \\
\hline $\operatorname{scorr}(\Delta \log \mathrm{Y})$ & 0.014 & 0.001 & -0.015 & 0.025 & 0.088 & -0.021 & -0.021 & 0.014 & 0.012 \\
\hline $\operatorname{corr}(\mathrm{I} / \mathrm{K}, \log (\mathrm{Y} / \mathrm{K}))$ & 0.407 & 0.275 & 0.402 & 0.406 & 0.756 & 0.414 & 0.549 & 0.412 & 0.418 \\
\hline $\operatorname{corr}(\Delta \log \mathrm{Y}, \log (\mathrm{Y} / \mathrm{K}))$ & 0.213 & 0.164 & 0.204 & 0.218 & 0.407 & 0.216 & 0.324 & 0.207 & 0.198 \\
\hline $\operatorname{corr}(\mathrm{I} / \mathrm{K}, \Delta \log \mathrm{Y})$ & 0.446 & 0.675 & 0.508 & 0.469 & 0.379 & 0.530 & 0.533 & 0.419 & 0.384 \\
\hline $\operatorname{Prop}(\mathrm{I} / \mathrm{K}>0.2)$ & 0.286 & 0.264 & 0.285 & 0.291 & 0.346 & 0.296 & 0.239 & 0.291 & 0.293 \\
\hline $\operatorname{Prop}(\mathrm{I} / \mathrm{K}=0)$ & 0.289 & 0.340 & 0.306 & 0.255 & 0.339 & 0.292 & 0.315 & 0.295 & 0.292 \\
\hline $\operatorname{Prop}(\mathrm{I} / \mathrm{K}<0)$ & 0.002 & 0.008 & 0.003 & 0.002 & 0.000 & 0.002 & 0.004 & 0.002 & 0.001 \\
\hline $\mathrm{OI}$ & 1051 & 4091 & 1374 & 1068 & 4132 & 1445 & 5136 & 1018 & 969 \\
\hline
\end{tabular}




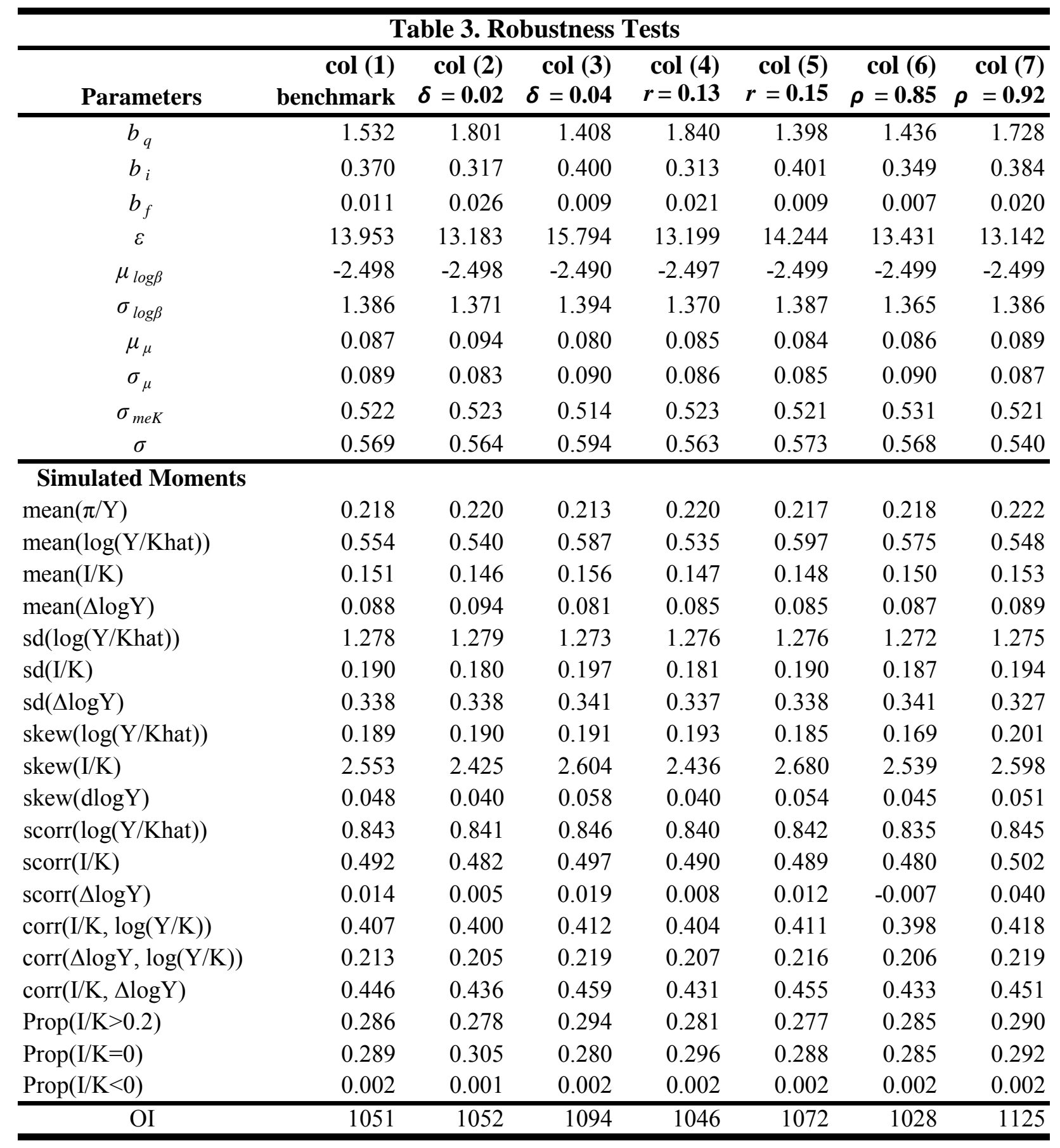




\begin{tabular}{|c|c|c|c|c|c|c|c|}
\hline & $\operatorname{col}(1)$ & $\operatorname{col}(2)$ & $\operatorname{col}(3)$ & $\operatorname{col}(4)$ & $\operatorname{col}(5)$ & $\operatorname{col}(6)$ & $\operatorname{col}(7)$ \\
\hline Parameters & full & MANU & SERVICE & LARGE & SMALL & BJ\&SH & GY\&LZ \\
\hline$b_{q}$ & 1.532 & 1.278 & 3.107 & 0.785 & 2.487 & 0.649 & 2.520 \\
\hline$b_{i}$ & 0.370 & 0.449 & 0.103 & 0.442 & 0.189 & 0.437 & 0.439 \\
\hline$b_{f}$ & 0.011 & 0.004 & 0.049 & 0.008 & 0.077 & 0.007 & 0.040 \\
\hline$\varepsilon$ & 13.953 & 16.343 & 10.502 & 15.581 & 12.506 & 18.792 & 13.970 \\
\hline$\mu_{\log \beta}$ & -2.498 & -2.499 & -2.447 & -2.487 & -2.430 & -2.497 & -2.349 \\
\hline$\sigma_{\log \beta}$ & 1.386 & 1.341 & 1.394 & 1.313 & 1.335 & 1.342 & 1.264 \\
\hline$\mu_{\mu}$ & 0.087 & 0.077 & 0.090 & 0.083 & 0.094 & 0.089 & 0.073 \\
\hline$\sigma_{\mu}$ & 0.089 & 0.068 & 0.122 & 0.076 & 0.100 & 0.051 & 0.074 \\
\hline$\sigma_{m e K}$ & 0.522 & 0.494 & 0.561 & 0.470 & 0.573 & 0.405 & 0.557 \\
\hline$\sigma$ & 0.569 & 0.611 & 0.501 & 0.541 & 0.593 & 0.622 & 0.622 \\
\hline \multicolumn{8}{|l|}{ Simulated Moments } \\
\hline $\operatorname{mean}(\pi / Y)$ & 0.218 & 0.204 & 0.246 & 0.205 & 0.229 & 0.198 & 0.226 \\
\hline mean $(\log (\mathrm{Y} /$ Khat $))$ & 0.554 & 0.506 & 0.698 & 0.331 & 0.838 & 0.738 & 0.088 \\
\hline $\operatorname{mean}(\mathrm{I} / \mathrm{K})$ & 0.151 & 0.122 & 0.201 & 0.128 & 0.178 & 0.161 & 0.131 \\
\hline $\operatorname{mean}(\Delta \log Y)$ & 0.088 & 0.078 & 0.091 & 0.084 & 0.094 & 0.091 & 0.078 \\
\hline $\operatorname{sd}(\log (Y /$ Khat $))$ & 1.278 & 1.229 & 1.344 & 1.226 & 1.303 & 1.206 & 1.231 \\
\hline $\operatorname{sd}(\mathrm{I} / \mathrm{K})$ & 0.190 & 0.165 & 0.237 & 0.165 & 0.235 & 0.200 & 0.160 \\
\hline $\operatorname{sd}(\Delta \log Y)$ & 0.338 & 0.340 & 0.332 & 0.342 & 0.358 & 0.343 & 0.340 \\
\hline skew $(\log (\mathrm{Y} /$ Khat $))$ & 0.189 & 0.220 & 0.186 & 0.182 & 0.190 & 0.159 & 0.237 \\
\hline skew $(\mathrm{I} / \mathrm{K})$ & 2.553 & 2.843 & 2.200 & 2.628 & 2.560 & 2.434 & 2.517 \\
\hline skew $(\mathrm{d} \log \mathrm{Y})$ & 0.048 & 0.085 & 0.063 & 0.043 & 0.075 & 0.154 & 0.101 \\
\hline $\operatorname{scorr}(\log (\mathrm{Y} /$ Khat $))$ & 0.843 & 0.838 & 0.848 & 0.852 & 0.824 & 0.888 & 0.807 \\
\hline $\operatorname{scorr}(\mathrm{I} / \mathrm{K})$ & 0.492 & 0.497 & 0.476 & 0.513 & 0.429 & 0.467 & 0.461 \\
\hline $\operatorname{scorr}(\Delta \log Y)$ & 0.014 & -0.012 & 0.059 & -0.027 & 0.023 & 0.016 & -0.001 \\
\hline $\operatorname{corr}(\mathrm{I} / \mathrm{K}, \log (\mathrm{Y} / \mathrm{K}))$ & 0.407 & 0.421 & 0.342 & 0.402 & 0.403 & 0.400 & 0.389 \\
\hline $\operatorname{corr}(\Delta \log \mathrm{Y}, \log (\mathrm{Y} / \mathrm{K}))$ & 0.213 & 0.218 & 0.177 & 0.217 & 0.213 & 0.248 & 0.201 \\
\hline $\operatorname{corr}(\mathrm{I} / \mathrm{K}, \Delta \log \mathrm{Y})$ & 0.446 & 0.455 & 0.398 & 0.472 & 0.442 & 0.587 & 0.350 \\
\hline $\operatorname{Prop}(\mathrm{I} / \mathrm{K}>0.2)$ & 0.286 & 0.219 & 0.397 & 0.229 & 0.347 & 0.307 & 0.246 \\
\hline $\operatorname{Prop}(\mathrm{I} / \mathrm{K}=0)$ & 0.289 & 0.297 & 0.291 & 0.213 & 0.366 & 0.283 & 0.321 \\
\hline $\operatorname{Prop}(\mathrm{I} / \mathrm{K}<0)$ & 0.002 & 0.002 & 0.002 & 0.003 & 0.001 & 0.001 & 0.000 \\
\hline $\mathrm{OI}$ & 1051 & 716 & 290 & 430 & 647 & 240 & 56 \\
\hline \multicolumn{8}{|l|}{ Other Information } \\
\hline estimated $\operatorname{Var}\left(\Delta \xi_{i, t}\right)$ & 0.617 & 0.581 & 0.672 & 0.515 & 0.731 & 0.436 & 0.709 \\
\hline imposed $\delta$ & 0.030 & 0.020 & 0.060 & 0.020 & 0.050 & 0.040 & 0.030 \\
\hline imposed $r$ & 0.140 & 0.150 & 0.110 & 0.120 & 0.160 & 0.170 & 0.080 \\
\hline imposed $\rho$ & 0.885 & 0.885 & 0.885 & 0.885 & 0.885 & 0.885 & 0.885 \\
\hline number of firms & 3618 & 2404 & 1214 & 1806 & 1812 & 553 & 274 \\
\hline median employees & 112 & 158 & 54 & 331 & 43 & 155 & 77 \\
\hline
\end{tabular}



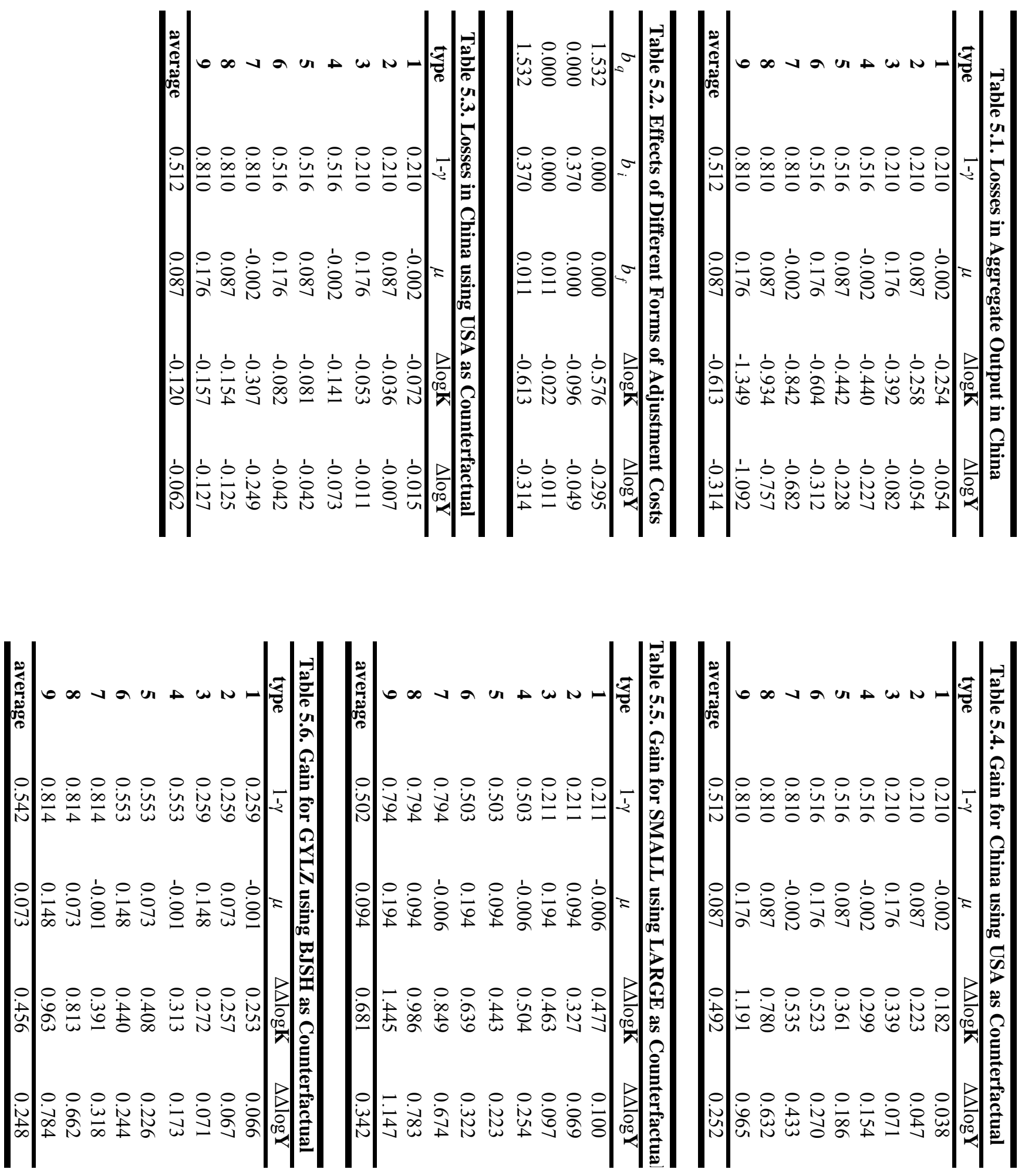